\title{
Intelligent Vehicle Charging Benefits Assessment Using EV Project Data ${ }^{*}$
}

$\begin{array}{ll}\text { S Letendre }^{\dagger} & \text { K Gowri } \\ \text { M Kintner-Meyer } & \text { R Pratt }\end{array}$

* Data compiled by Idaho National Laboratory

${ }^{\dagger}$ Green Mountain College, Poultney, VT

December 2013

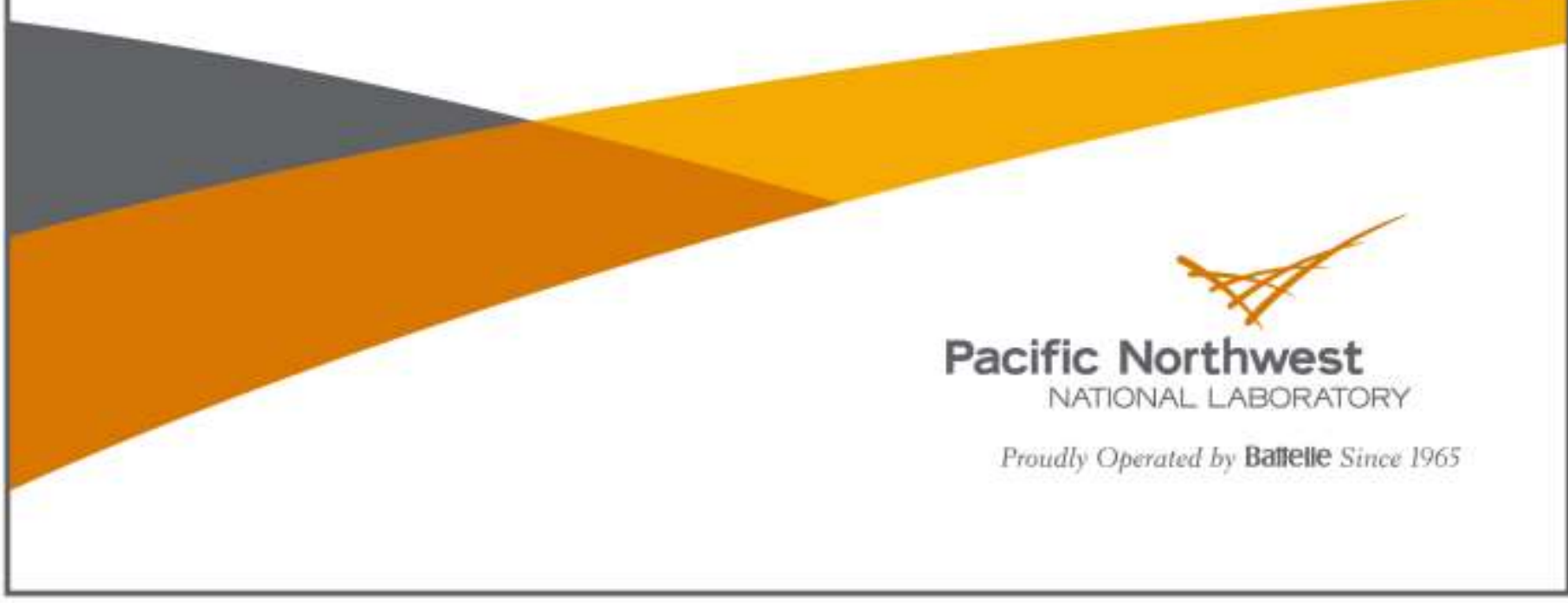




\title{
DISCLAIMER
}

This report was prepared as an account of work sponsored by an agency of the United States Government. Neither the United States Government nor any agency thereof, nor Battelle Memorial Institute, nor any of their employees, makes any warranty, express or implied, or assumes any legal liability or responsibility for the accuracy, completeness, or usefulness of any information, apparatus, product, or process disclosed, or represents that its use would not infringe privately owned rights. Reference herein to any specific commercial product, process, or service by trade name, trademark, manufacturer, or otherwise does not necessarily constitute or imply its endorsement, recommendation, or favoring by the United States Government or any agency thereof, or Battelle Memorial Institute. The views and opinions of authors expressed herein do not necessarily state or reflect those of the United States Government or any agency thereof.

\author{
PACIFIC NORTHWEST NATIONAL LABORATORY \\ operated by \\ BATTELLE \\ for the \\ UNITED STATES DEPARTMENT OF ENERGY \\ under Contract DE-AC05-76RL01830
}

Printed in the United States of America
Available to DOE and DOE contractors from the Office of Scientific and Technical Information,
P.O. Box 62, Oak Ridge, TN 37831-0062;
ph: (865) 576-8401
fax: $(865)$ 576-5728
email: reports@adonis.osti.gov

\begin{abstract}
Available to the public from the National Technical Information Service, U.S. Department of Commerce, 5285 Port Royal Rd., Springfield, VA 22161 ph: (800) 553-6847 fax: $(703) 605-6900$ email: orders@ntis.fedworld.gov online ordering: http://www.ntis.gov/ordering.htm
\end{abstract}

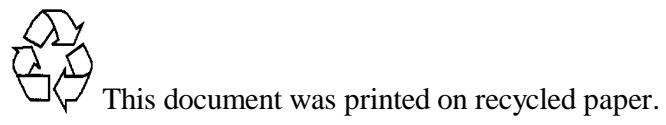




\title{
Intelligent Vehicle Charging Benefits Assessment Using EV Project Data \\ * Data compiled by Idaho National Laboratory
}

\author{
S Letendre ${ }^{\dagger}$ \\ K Gowri \\ M Kintner-Meyer \\ R Pratt \\ $\uparrow^{\dagger}$ Green Mountain College, Poultney, VT
}

December 2013

Prepared for

the U.S. Department of Energy

under Contract DE-AC05-76RL01830

Pacific Northwest National Laboratory

Richland, Washington 99352 


\section{Executive Summary}

Plug-in electric vehicles (PEV) offer the near-term opportunity to displace gasoline purchased at the pump with electricity purchased from the grid and generated from diverse domestic resources. Dozens of studies have been conducted over the past decade exploring the emissions benefits, grid impacts, and potential role that PEVs could play as distributed energy sources. These studies are largely based on various scenarios when PEVs become a sizable part of the nation's light-duty vehicle fleet. In addition, many of these studies highlight the importance of an infrastructure that allows communication and control between the PEV, electric vehicle supply equipment (EVSE) and the emerging smart grid. Here, this is referred to as an intelligent vehicle charging infrastructure (IVCI). This report estimates the lost opportunities of PEV charging applying intelligent charging strategies and using the most recent and extensive charging behavior data available in the U.S.

The EV Project funded through the U.S. Department of Energy (DOE) represents the largest PEV and EVSE deployment in the nation's history, which includes an extensive data collection effort undertaken by Idaho National Laboratory. With data on over 2.3 million charging events, much is being learned about PEV charging behaviors and the impacts on regional grids. The PEV infrastructure being currently deployed does not include control capabilities across the infrastructure other than vehicle-based timers.

\section{Scope:}

This study focuses on a high-level assessment of the economic benefits of an IVCI using EV Project data. The following grid impacts and lost economic benefits are analyzed in this study, assuming that an IVCI is available:

- the potential of increased regional peak demand for power in regions without time-of-use (TOU) rates,

- reduced costs of PEV charging from shifting timing to off-peak periods,

- significant ramping of PEV charging load when off-peak TOU rates take effect, leading to potential distribution constraints,

- potential economic benefits from participating in wholesale markets for reserve capacity.

\section{Grid Impact}

EV Project data demonstrates that participants in regions without TOU rates begin charging their vehicles when returning home from the daily commute. In some regions and during certain times of the year, the start of PEV charging coincides with the system peak. Data from Texas and the mid-Atlantic coast demonstrates the coincidence between PEV charging and regional system peaks during the first quarter of 2013. The results are mixed when the timing of annual peak load is compared to the peak demand associated with PEV charging. In Houston and Washington DC, the peak demand for PEV charging lags the 2012 annual system peaks by several hours. In the Dallas-Ft. Worth region, however, the coincidence of peak demand and PEV charging found in the first quarter of 2013 is consistent with the 2012 annual peak load. In any case, home charging 
is contributing either coincidently or with a small delay to the system peak imposing additional stress to the electric power system, particularly during hot summer days.

The effective demand for EV Project participants is calculated and used to estimate the percentage increase in regional system loads from an additional 500,000 PEVs based on data from the first three months of 2013. In the Houston metropolitan region of Texas the regional grid could experience a 5 percent increase in peak demand while the Dallas-Fort Worth region could experience a 3 percent increase in the system peak. In Washington DC and Philadelphia, PA 500,000 additional PEVs could increase the Eastern PJM system peak by over one percent. Finally, 500,000 additional PEVs in the Washington State EV Project region could increase system peak by just over 7 percent ${ }^{1}$. These estimates are based on the first quarter of 2013 PEV charging load and regional system loads and would not necessarily apply to annual peak loads. Thus, as PEV adoption rates increase in the coming decade, additional investments in generation, transmission and distribution infrastructure could be required unless strategies are put in place to either directly or indirectly shift vehicle charging to the late evening and early morning hours.

PEV charging by EV Project participants that occurs during peak demand periods is more costly than if charging occurred off-peak as rates are historically lower during the late evening and early morning hours. The annual reduced costs of PEV charging from shifting $23 \mathrm{MWh}$ of the current daily consumption of the EV fleet to off-peak periods is estimated to be between $\$ 170,000$ to $\$ 1.3$ million assuming a rate differential between peak and off-peak periods of $\$ 0.02 / \mathrm{kWh}$ and $\$ 0.15 / \mathrm{kWh}$ respectively. Over 10 years, the per vehicle charging cost savings are estimated to be between $\$ 450$ to $\$ 3,300$ dollars in present value terms, again assuming the above peak versus off-peak rate differentials.

Data on charging behaviors gathered through the EV Project clearly illustrates that TOU rates act as an effective incentive for off-peak charging. However, the degree to which consumers respond may depend on the level of the peak versus off-peak rate differential. Additional research is needed to better understand the level of peak versus off-peak rate differential to elicit the desired consumer charging behavior. These differentials can vary considerably between utility companies for example the Los Angeles Department of Power and Water offers an EV charging rate with a $2.5 \mathrm{c} / \mathrm{kWh}$ rate differential as compared to utilities in San Francisco and San Diego, both of which have much higher peak versus off-peak rate differentials of over $10 \notin / \mathrm{kWh}$.

In the California regions with TOU rates, there is a sharp spike in demand for PEV charging precisely at the time when the off-peak rate takes effect. This sudden spike in demand for PEV charging could lead to local power demands exceeding the capacity limits of secondary transformers in certain PEV neighborhood clusters with coincidental charging behaviors. While the costs to upgrade distribution infrastructure is very site specific, no attempt is made to estimate these values. However, it is recognized that the IVCI could allow grid operators to stagger PEV charging in those neighborhoods with PEV clusters thus avoiding any potential distribution system upgrade costs.

\footnotetext{
${ }^{1}$ To provide a sense of time until 500,000 PEV may be on the road, we estimated for WA-State that it would take about 7 years to growth from currently 5000 PEV registered in WA-State at an annual growth rate of 100\%, which is less than the actual growth rate from 2011 to 2012 of 143\% in WA-State.
} 
One of the biggest lost economic benefits from not having an IVCI in place is the inability for PEVs to participate as grid resources in regional wholesale power markets. PEVs could potentially provide grid services such as peak-shaving in transmission and distribution systems, reserve capacity, and renewable generation balancing. These market opportunities are not yet available to PEV owners primarily due to lack of IVCI and the corresponding technology in vehicles to serve as distributed energy sources. At least one major automobile manufacturer is experimenting with prototype vehicles with $\mathrm{V} 2 \mathrm{G}$ capabilities, but none are currently offered to the general car-buying public. The uncertain impact on battery life from using PEVs to provide grid support services may be a barrier to future commercialization of V2G services. Furthermore, there are no current business models designed specifically to monetize potential V2G services.

The potential benefits of EV Project vehicles assuming they have the ability to participate in wholesale markets for regulation and spinning reserve are estimated to be between $\$ 221,000$ to $\$ 7.5$ million annually (gross revenue potential) depending on the power rating of the grid connection, hours participating in markets, and the service provided. The low range is based on the EV Project PEV fleet providing spinning reserves based on the lowest annual average prices from various wholesale power markets in 2011 of $\$ 3.37$ MWh for 2,190 hours a year with a $5 \mathrm{~kW}$ power vehicle-to-grid (V2G) grid connection. In contrast, the high end of the range is based on the highest 2011 market prices for providing regulation services of \$16.42/MW-h for 5,081 hours a year with a $15 \mathrm{~kW} \mathrm{V2G}$ grid connection. On a per vehicle basis, the present value lost benefit over 10 years from not having the ability to provide grid support services in regional wholesale power markets ranges from $\$ 1,400$ to $\$ 6,700$. These values are based on the minimum and maximum average 2011 wholesale ancillary services prices, with a $10 \mathrm{~kW}$ V2G grid connection, and providing services for 5,081 hours in the year, which translates to about 14 hours of V2G operations every day. This would require perhaps additional EVSE units in office parking lots to allow vehicle owners to provide grid services when parked at work.

This study does not consider the economic costs associated with battery degradation resulting from increased cycling to provide V2G services. The impacts on battery life depend on the battery chemistry and type of grid services being offered, and several other factors which are beyond the scope of this study. Future improvements in battery technology and development of battery impact mitigation strategies will likely be needed to minimize the costs of providing V2G services. Additional research is needed in this area to better assess the market potential of V2G.

For V2GHalf, whereby no electricity is fed back into the grid, simply modulating the rate of charge, the benefit potential is limited up to half of that for the full V2G scenario, thus approximately $\$ 680$ - $\$ 3,325$ over a 10 year period. In this case there would be no negative impacts on vehicle battery life due to increased cycling. This scenario is feasible today given the existing fleet of PEVs being sold; and V2GHalf services could conceivably be delivered by existing energy services and demand response providers if reasonable financial returns were achievable.

The economic benefits of an IVCI are substantial. These will rise significantly as PEV penetration rates accelerate in the coming decades. It is essential that relevant stakeholders evaluate these economic benefits and costs to develop the necessary communication and control standards to develop a nation-wide IVCI. 



\section{Table of Contents}

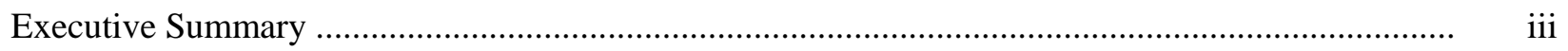

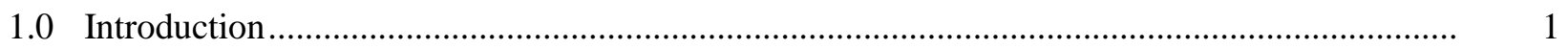

2.0 The Economic Value of an Intelligent Vehicle Charging Infrastructure .................................. 5

3.0 PEV Charging Load Timing: The Value of IVCI ...............................................................

3.1 PEV Charging Load vs. System Load Analysis without TOU Rate Options ..................... 8

3.2 PEV Charging Load Timing in Areas with TOU Rate Options ....................................... 17

4.0 Providing Grid Support Services Using an IVCI and V2G Systems ..................................... 21

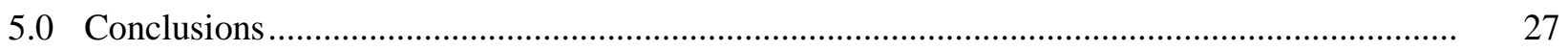

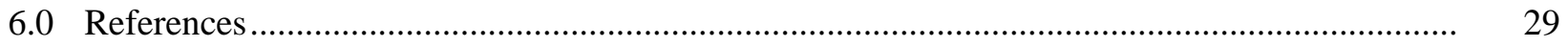

\section{List of Figures}

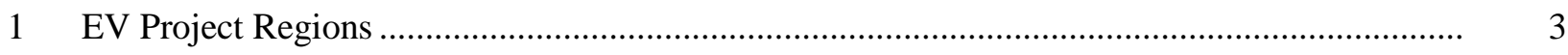

2 Grid Interactive Vehicle Value Chain ............................................................................. 5

3 PEV Charging Load Q1 2013 All Regions and all Charging Locations ................................... 7

4 Dallas-Ft. Worth Charge Load vs. Average Hourly System Load Q1 2013 ............................. 8

$5 \quad$ Houston Charge Load vs. Hourly Average System Load Q1 2013 .......................................... 9

6 Washington DC Charge Load vs. Average Hourly System Load Q1 2013 .............................. 9

$7 \quad$ Philadelphia Charge Load vs. Average Hourly System Load Q1 2013 …............................... 10

8 Washington State Charge Load vs. Average Hourly System Load Q1 2013 ............................ 10

9 Oregon Charge Load vs. Average Hourly System Load Q1 2013 ............................................ 11

10 San Diego Charge Load vs. Average Hourly System Load Q1 2013 ...................................... 11

11 Dallas-Ft. Worth Charge Load Q3 2012 vs. Regional System Peak 2012 ............................... 12

12 Houston Charge Load Q3 2012 vs. Regional System Peak 2012 ............................................. 12

13 Washington, DC Charge Load Q3 2012 vs. Regional System Peak 2012 ................................ 13

14. Percent Increase in Regional Peak Load with 500,000 PEVs ................................................... 14

15 Charge Load vs. Charge Load Adjusted Q1 2013 ................................................................ 15

16 Normalized Charge Load, Charge Load Adjusted and PJM System Peak Day Q1 2013 ........... 16

17 Normalized Median Charging Load CA Regions Q1 2013 ..................................................... 17

18 Peak Charge Load and Adjusted Charge Load San Francisco Q1 2013 ................................... 19

19 Percent of Residential Level 2 Chargers with Vehicle Connected by Time of Day ................... 22

20 Percent of Away Level 2 Chargers with Vehicle Connected by Time of Day ........................... 22

21 Present Value Gross Revenue per Vehicle Providing Grid Services 2011 Min. and Max.

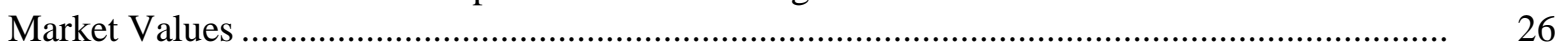




\section{List of Tables}

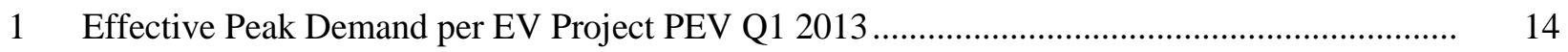

2 Annual PEV Charging Savings for PV Project Vehicles Moving to TOU Rates ...................... 16

3 EV Project Statistics on EVSE Use Over Five Quarters ...................................................... 21

4 Annual Average Market Clearing Prices 2011 for Regulation and Spinning Reserves .............. 24

5 Revenue Potential for EV Project Vehicle Fleet Providing Regulation Services

Applying Full V2G Capabilities.......................................................................................... 24

6 Revenue Potential for EV Project Vehicle Fleet Providing Spinning Reserve

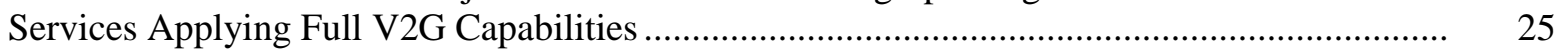




\subsection{Introduction}

Today, over 90 percent of vehicle travel is fueled using petroleum-derived fuels. Rising costs, emissions concerns, and the national security risks of relying on petroleum-based fuels (40 percent of which is imported into the US) creates an incentive to find ways to diversify the energy sources that fuel the nation's light vehicle fleet. One of the best, near-term options to diversify fuels used in light vehicles is to transition to electric propulsion.

For the first time in over a decade, consumers have several vehicle options that provide the opportunity to displace gasoline purchased at the pump with electricity purchased from the grid. Virtually every major automobile manufacturer currently, or has plans to do so soon, offers a plug-in vehicles (PEVs) for sale to the car-buying public. The PEVs currently available come in different configurations from the all-electric Nissan Leaf to the GM plug-in hybrid Volt with a gasoline engine to extend the range of the vehicle. There are currently several other PEV options available to consumers, with more being introduced each year. While PEV sales still only represent less than one percent of new vehicle sales, the hybrid sales tracking web site, Hybridcars.com reports that the sale of PEVs in the first six months of 2013 is up by 164 percent relative to the first six months of 2012.

Several studies have been conducted to assess the likely grid impacts of a growing fleet of PEVs on the nation's electric power system. Kintner-Meyer et al. (2007) estimated the percentage of the light-duty vehicle (LDV) fleet that could be supplied with energy from the existing U.S. power system without additional investments in generation, transmission, and distribution infrastructure. They evaluated the off-peak idle capacity and the demand for electricity for vehicle charging. They found that the existing idle generation capacity is capable of charging 73 percent of the existing LDV fleet. Furthermore, they project the gasoline displacement potential to be 6.5 million barrels of oil equivalent per day, or 52 percent of the nation's oil imports at the time the report was published.

In contrast, Hadley and Tsvetkova (2008) modeled several different PEV charging scenarios, including evening charging starting at 5:00 pm and nighttime charging beginning at 10:00 pm. They found that the evening charging scenario, especially at high power levels, could impact the overall peak demand for power and reduce reserve margins in regional power systems. The nighttime charging scenario analyzed did not impact peak power demand, but would impact the amount and type of generation utilized. Essentially, both studies confirmed that off-peak charging is a key strategy to minimize the power grid impacts from the electrification of the LDV fleet in the U.S. Furthermore, the nation's grid can supply electricity to displace significant volumes of gasoline used for transportation using the existing generation, transmission, and distribution infrastructure if the majority of vehicle charging occurs off-peak.

While the bulk power supply infrastructure is adequate to charge a large number of PEVs offpeak, there is the potential for PEV clusters in certain neighborhoods to place strain on the local distribution network even at low overall PEV penetration rates. Researchers at the Electric Power Research Institute are conducting a multi-year collaborative research project to study PEV impacts and integration on utility distribution systems. Taylor et al. (2010) finds that the extent of system impacts depends upon the PEV penetration and charge behaviors and that PEV 
neighborhood clusters or coincidental charging behaviors could result in loads beyond what current circuit design can reliably serve.

A significant literature has developed over the past decade on the value that PEVs can provide serving as distributed energy storage devices. Kempton and Letendre (1997) developed the analytical framework for assessing PEVs as grid resources and identified the various grid services that PEVs could potentially provide. These so called vehicle-to-grid (V2G) services require a bi-directional interface between the electric vehicle supply equipment (EVSE) and the power grid, and take advantage of the fact that vehicles are idle approximately 90 percent of the time. Letendre et al. (2006) finds that a single PEV could generate gross annual revenue ranging from $\$ 200$ to over $\$ 3,000$ annually depending on the service provided and the power rating of the V2G interface. Furthermore, Kempton and Tomic (2005) and Tuffner and Kintner-Meyer (2011) explore the use of PEVs with V2G capability to address the intermittent nature of renewable generation including wind and solar.

To date, the majority of research on the grid impacts of PEV charging and the value of V2G services is based on various future PEV penetration scenarios. While the penetration of PEVs is still low relative to conventional vehicles, we are gaining experience on PEV usage and charging behaviors from the several thousand PEVs that have already been sold. The EV Project is a federally funded initiative with several private sector partners representing the largest PEV and EVSE deployment in history. ECOtality Inc. was the recipient of U.S. Department of Energy funds totaling \$115 million dollars and raised an additional \$115 million from industry partners for a total project budget of $\$ 230$ million; ECOtality is responsible for planning and administering the EV Project with the Idaho National Laboratory compiling and analyzing the data collected from EV Project participants.

The EV Project involves deploying Nissan Leafs and GM Volts in several regions across the country (see Figure 1) with qualifying consumers and the associated EVSE infrastructure. As stated on the EV Project web site:

"The EV Project collects and analyzes data to characterize vehicle use in diverse topographic and climatic conditions, evaluates the effectiveness of charge infrastructure, and conducts trials of various revenue systems for commercial and public charge infrastructures. The ultimate goal of the EV Project is to take the lessons learned from the deployment of the first thousands of EVs, and the charging infrastructure supporting them, to enable the streamlined deployment of the next generation of EVs to come." (http://www.theevproject.com/overview.php). 


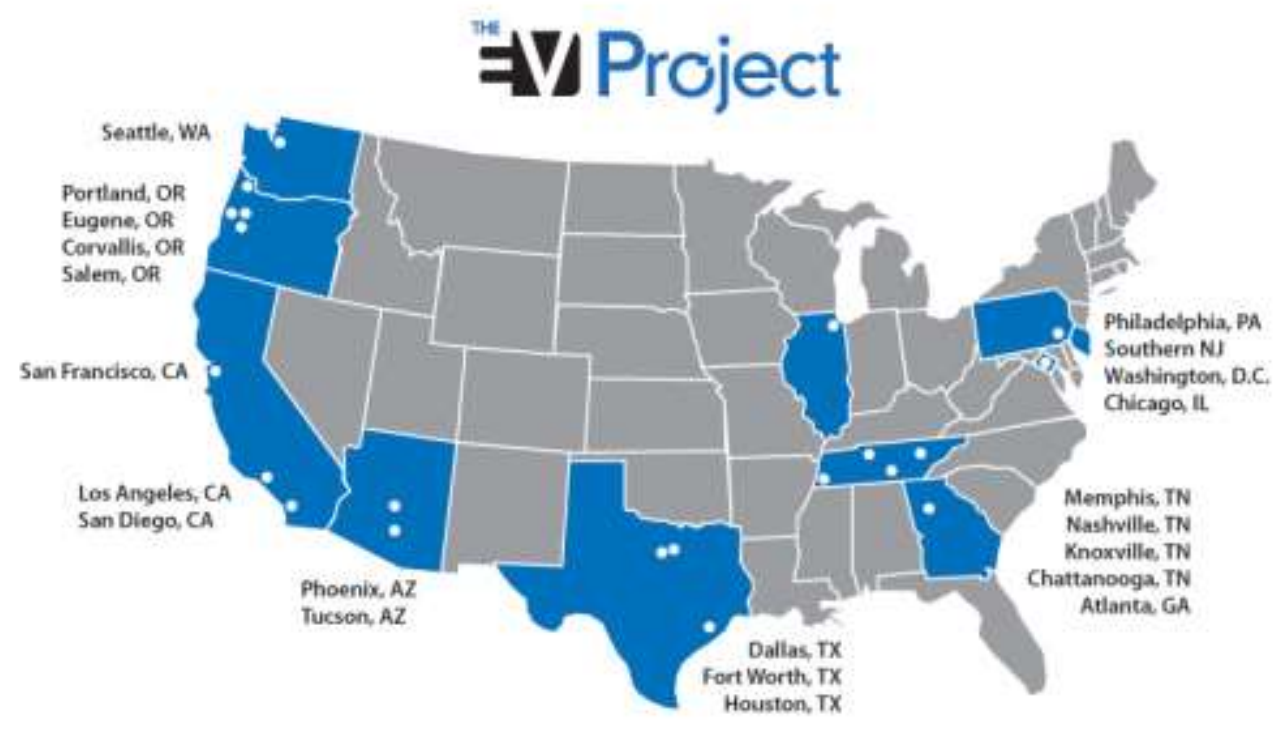

Figure 1. EV Project Regions

Consumers that join the EV Project agree to allow the collection of vehicle use and charging related information. The information collected through the EV Project includes data from both the vehicle and the EVSE, including energy used and time and duration of charger use. The EV Project explicitly states that no personal information will be shared or included in the data from the project that is disseminated in various ways.

At the end of the first quarter in 2013, the EV Project published the following project statistics in their Q1 2013 report:

- 75 million miles recorded to date on EV Project vehicles

- Over 2.3 million charging events recorded to date

- Over 19,500 Megawatt hours of energy delivered to EV Project vehicles to date

- 7,937 Nissan Leafs, Chevrolet Volts and Smart ForTwo Electric Drive vehicles participating

- 8,278 Residential EVSE installed

- 3,166 Commercial (publicly available, workplace and fleet) EVSE installed

- 76 DC Fast Chargers installed

The infrastructure being deployed as part of the EV Project does not yet include advanced communications and control capabilities. An intelligent vehicle charging infrastructure (IVCI) requires seamless communication and control from the car to and from the EVSE, and ultimately tied into the regional grid operator's SCADA system. To date, however, the lack of interoperability standards for the emerging PEV infrastructure components represents perhaps one of the biggest challenges to the development of an IVCI. 
A rich literature has emerged in the past decade suggesting that the system benefits of an IVCI could be substantial. These include using optimal charging algorithms to avoid distribution infrastructure constraints, least cost charging with interactive time-of-use (TOU) rates, demand response services, and the provision of additional V2G services including frequency regulation and spinning reserves. EV Project data on vehicle charging and infrastructure use is applied to investigate the current and future grid impacts and lost economic benefits associated with not having in place an IVCI. This analysis serves to highlight the importance of moving more quickly to develop interoperability standards between EV, EVSE, and the emerging smart grid infrastructure. 


\subsection{The Economic Value of an Intelligent Vehicle Charging Infrastructure}

The nation's existing electric power infrastructure has the capacity to charge a large number PEVs, provided that the majority of vehicle charging is delayed to off-peak periods. Vehicle charging represents the single largest new load to appear on the nation's grid in decades. The inherent nature of PEVs with the on-board storage allows for flexibility with the timing of vehicle charging during the nighttime and early morning hours while still providing a full charge for the daily commute. This flexibility can be exploited to minimize the unwanted grid impacts from vehicle charging and to improve system operations using an IVCI systems providing V2G services. The economic and power system benefits of intelligent vehicle charging and $\mathrm{V} 2 \mathrm{G}$ have been studied and are currently being documented in several regional demonstrations. These benefits will not be broadly realized, however, until communication and control standards across the PEV infrastructure are in place.

Figure 2 below illustrates the various segments of the grid interactive vehicle value chain. The transfer of information on vehicle battery state of charge (SOC), vehicle location, and owner preferences with regard to miles of charge needed and willingness to participate as a demand response resource or provide V2G services needs to flow through to the retail energy provider or aggregator that is linked with the regional grid operator. Aggregated data from hundreds or thousands of vehicles can be monetized through the provision of grid services to the ISO/RTO. To facilitate these transactions the entity providing the aggregation service must be able to locate and identify the metered account and send control signals through the smart meter to the EVSE or directly to the EVSE.

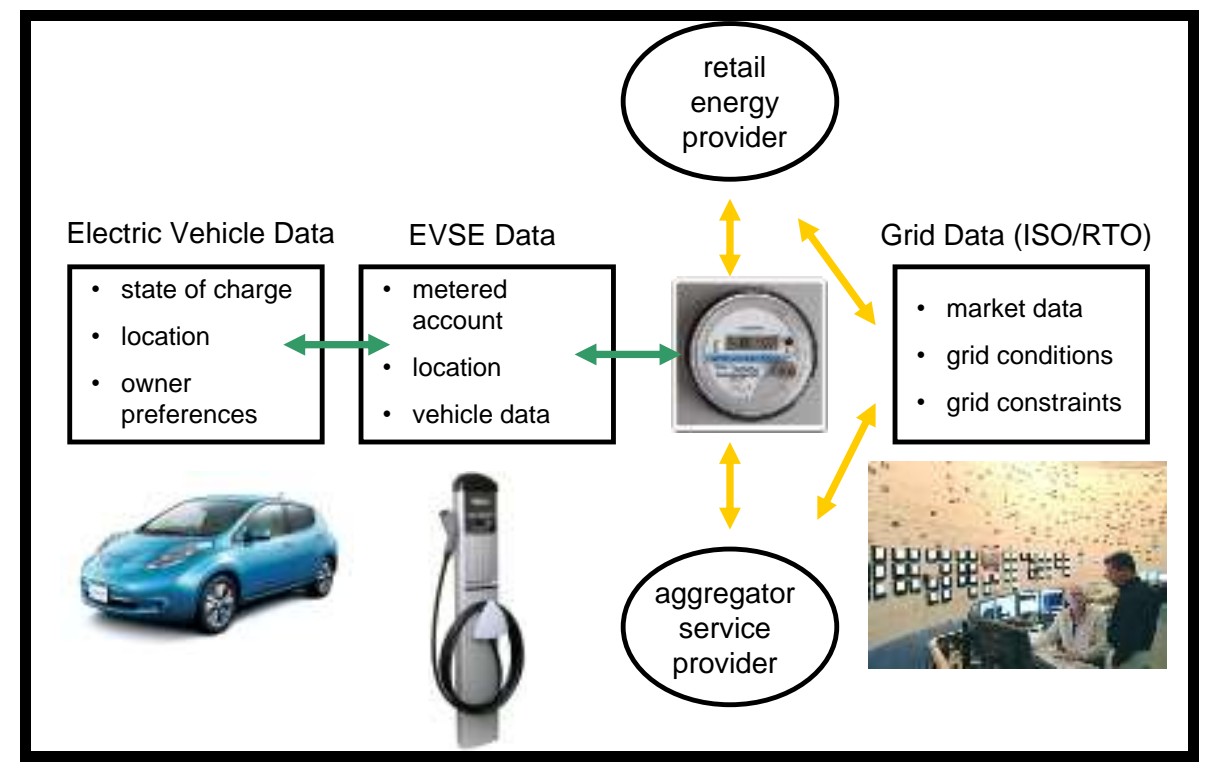

Figure 2. Grid Interactive Vehicle Value Chain

This paper analyzes the economic value that an intelligent vehicle charging infrastructure (IVCI) can deliver. Actual charging and EVSE usage from EV Project data is used to provide a high-level assessment of the current and future lost opportunities from the lack of a nation-wide 
IVCI. The economic value of an IVCI is divided into two broad categories: managing charging load timing and the provision of grid support services.

An IVCI can be deployed to manage the timing of PEV charging, which provides economic value to ratepayers by minimizing infrastructure investments and to PEV owners through lowcost charging strategies. Shifting charging to off-peak periods either indirectly through time-ofuse (TOU) rates or directly through utility control can defer investments in generation, transmission and distribution infrastructure. Furthermore, this allows greater utilization of the existing grid infrastructure (e.g., amortizing existing investments over a larger number of MWh delivered). Scott et al. (2007) finds that PEV adoption can overtime place downward pressure on average prices for electricity if off-peak charging occurs to increase the capacity factors of generation, transmission, and distribution assets.

As discussed below, EV Project data suggests that TOU rates are proving to be an effective mechanism to encourage off-peak charging. However, the data suggests a large spike in demand precisely at the time the off-peak rates goes into effect; an earlier study by Wu et al. (2012) predicted this possible result of increasing off-peak PEV charging. This can increase the regional balancing costs due to the large ramp needed to meet the demand spike for PEV charging when the off-peak rate goes into effect. As discussed above, local demand spikes place strain on the distribution infrastructure in neighborhoods with PEV clusters. Over loaded circuits and transformers may require upgrades at an expense to rate payers from off-peak charging without an IVCI. Direct utility controlled charging using the IVCI could stagger the charging of vehicles thus reducing generator ramp rates and the associated balancing cost and, within certain neighborhood PEV clusters, avoid investments in distribution infrastructure. The value of staggering PEV charging based on system needs and constraints is very site specific, and thus this study recognizes the potential value, but no attempt is made to estimate these potential costs.

The second broad category of economic value that an IVCI can provide is through the provision of grid support services using V2G systems. Currently, the grid has very little capacity to store electricity, thus the entire system is designed to match production and consumption continuously in real time. A host of grid services, beyond bulk power generation transmission and distribution, are required to meet reliability standards. These are generally referred to as ancillary services, including frequency response regulation, spinning reserves, and non-spinning reserves. In regions with competitive wholesale power markets these services are often unbundled and procured competitively through day-ahead and real time wholesale markets. Increasingly utilities have been turning to demand-side resources to deliver reliability services, so called demand response. As discussed above, PEVs provide a readily available capability to store energy to address the intermittent nature of renewable generation. The expansive V2G literature finds no major technical barriers to PEVs providing these services.

An IVCI with V2G capabilities can provide value to consumers on the demand-side of the meter as well. PEVs can provide peak-shaving and the associated demand charge savings for commercial and industrial customers. In addition, PEVs can provide a source of emergency back-up power for critical loads and enhance power quality for sensitive loads. Again, while we recognize the economic value that PEVs can provide on the customer side of the meter, these are very utility- and customer-specific and are not evaluated in this study. 


\subsection{PEV Charging Profile: The Value of IVCI}

With over a 2.3 million charging events on record, EV Project data provides insights into vehicle charging behaviors and EVSE usage patterns. Figure 3 illustrates the demand for vehicle charging during a typical weekday for all vehicles across all regions where participating EV Project vehicles are located based on data from the 2013 Q1 EV Project Vehicle Charging Infrastructure Summary Report (INL3, 2013). This represents the daily minimum, median, and peak demand for charging the 6,006 EV Project vehicles during the first quarter of 2013 at all charging locations (8,500 charging units) and averaged over 501,193 charging events.

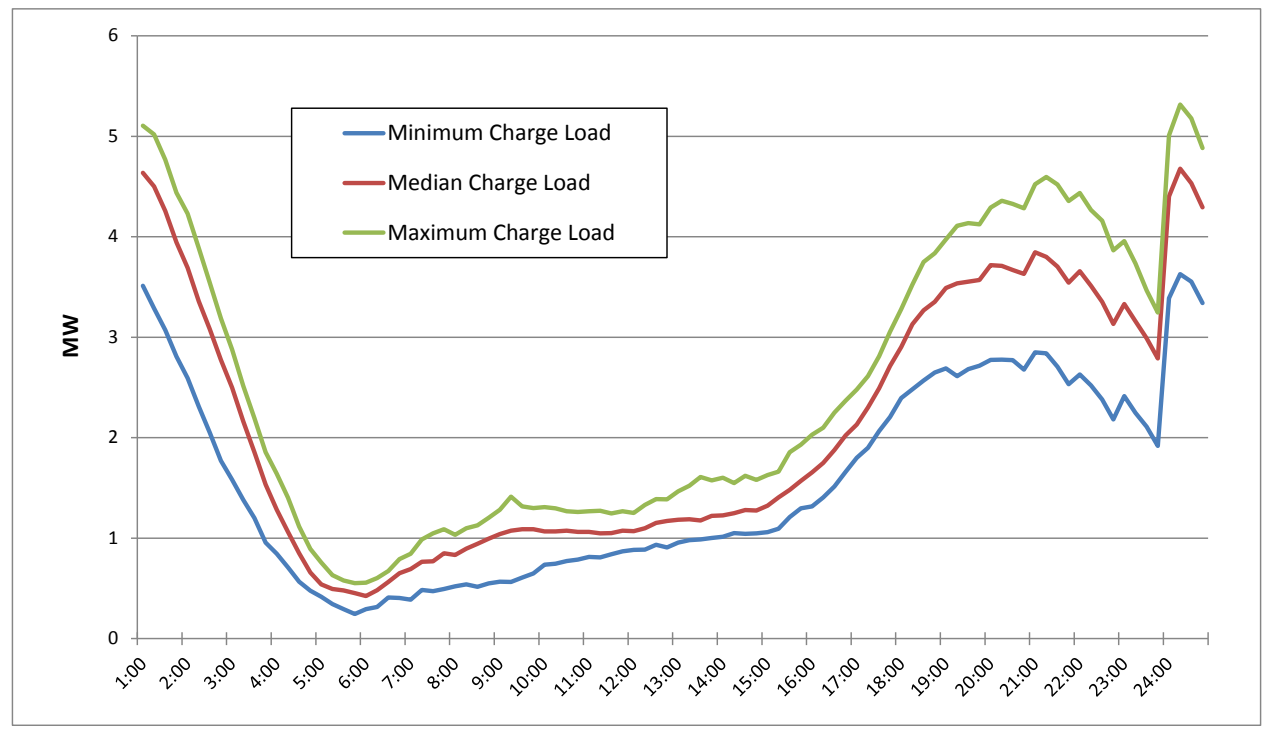

Figure 3. PEV Charging Load Q1 2013 All Regions and all Charging Locations

Several observations can be made from Figure 3 above. Many EV Project vehicle owners begin charging when arriving home from the daily commute. The demand for vehicle charging begins climbing precipitously at 5:00 pm and peaks around 9:00 pm. Vehicle charging then reaches a new peak around 12:00 am when off-peak-rates take effect in certain utility service territories. Demand for PEV charging begins to drop precipitously at 2:00 am; the lowest demand for vehicle charging occurs between 4:00 am and 9:00 am and rises gradually during the daytime hours as some PEV owners connect to EVSE units away from the home.

Another important observation from the data is that there is significant daily variation in the hourly demand for vehicle charging. The biggest range between the hourly minimum and maximum loads is $1.8 \mathrm{MW}$, which occurs at 9:00 pm.

Next, data is analyzed from several case study regions including those without and with TOU rates. 


\subsection{PEV Charging Load vs. System Load Analysis Without TOU Rate Options}

Several regions where EV Project participants are located do not offer TOU rates to customers. In these regions PEV owners tend to begin vehicle charging when they return home in the evening from the daily commute. Here normalized vehicle charging load profiles are compared to normalized system loads to assess the coincidence between peak charging load and system load. Normalized loads are calculated by taking each 15 minute load value recorded through the EV Project and dividing it by the maximum value; a value of one indicates the time of day when the demand for PEV charging is highest. Seven regions are considered: Dallas/Fort Worth TX, Houston, TX, Washington, DC, Philadelphia, PA, Washington State, Oregon, and San Diego, CA.

Figure 4 and Figure 5 compare the normalized loads for PEV charging in the Dallas-Fort Worth and Houston Texas regions, with 189 and 75 EV Project vehicles respectively as of the first quarter of 2013, with the average hourly system load from historical ERCOT (Electric Reliability Council of Texas) data. The normalized median charging loads for both regions are based on EV Project data from the first quarter of 2013. The normalized average hourly system loads for the north central (Dallas-Ft. Worth) and coast (Houston) regions were calculated from hourly data for the first three months of 2013, which were obtained from the ERCOT web site.

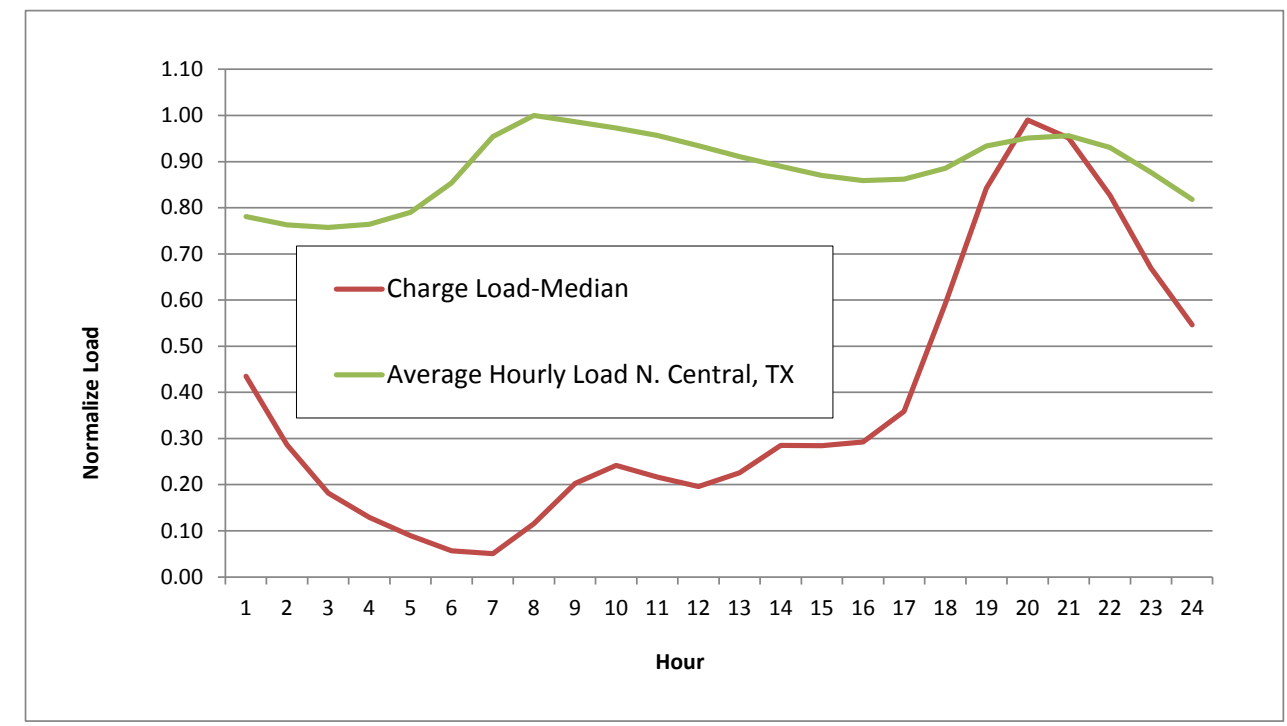

Figure 4. Dallas-Ft. Worth Charge Load vs. Average Hourly System Load Q1 2013 


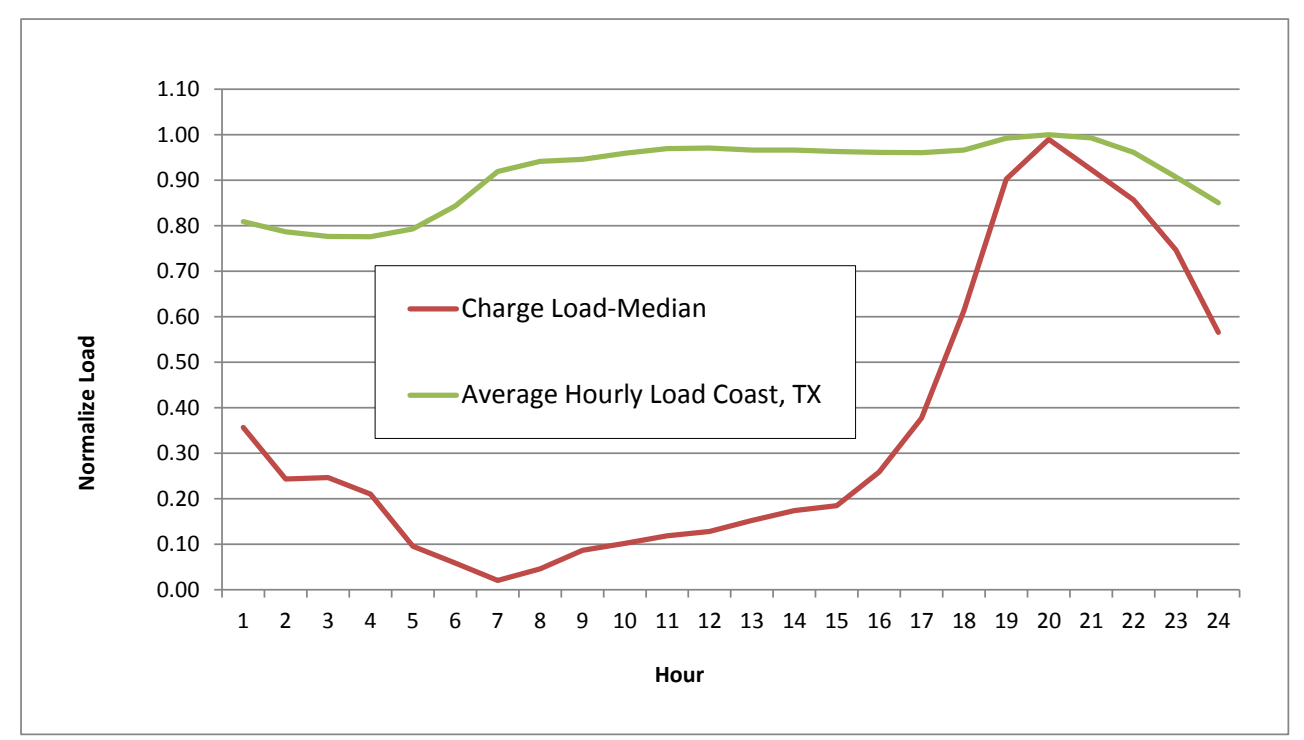

Figure 5. Houston Charge Load vs. Hourly Average System Load Q1 2013

Figure 6 and Figure 7 compare the normalized loads for PEV charging in the Washington, DC and Philadelphia, PA regions, with 297 and 67 EV Project vehicles respectively as of the first quarter of 2013, with the average hourly system load from historical PJM data. The normalized median charging loads for both regions are based on EV Project data from the first quarter of 2013. The normalized average hourly system load for Washington DC and Philadelphia, PA were calculated from hourly system load data for the eastern PJM region for the first three months of 2013, which were obtained from the PJM web site.

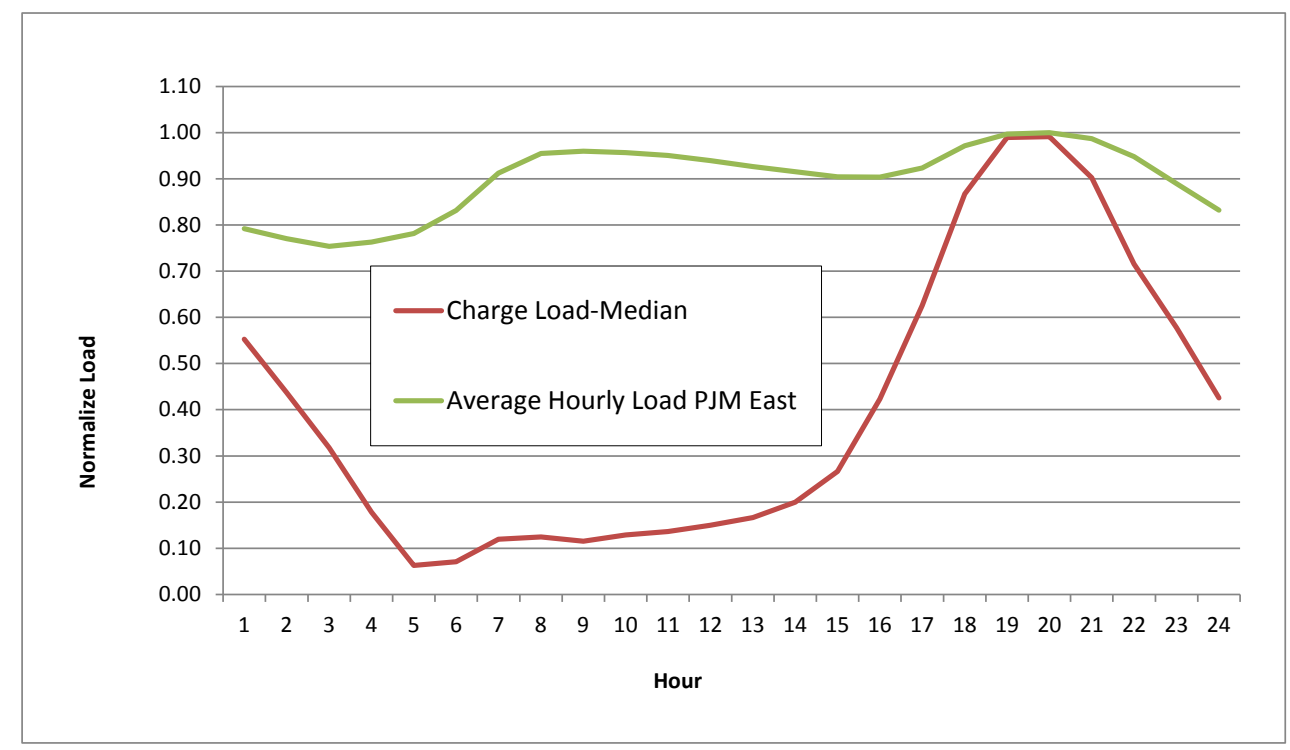

Figure 6. Washington DC Charge Load vs. Average Hourly System Load Q1 2013 


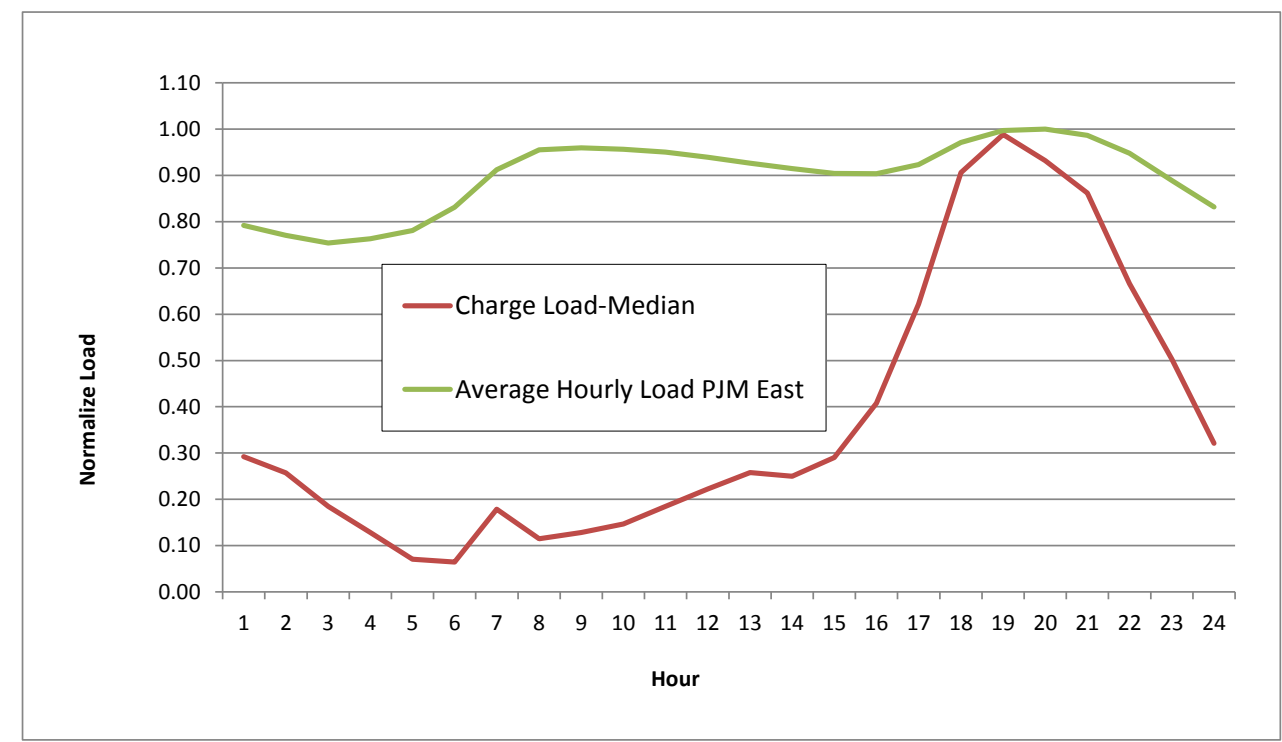

Figure 7. Philadelphia Charge Load vs. Average Hourly System Load Q1 2013

Figure 8 and Figure 9 compare the normalized loads for PEV charging in Washington State and Oregon, with 807 and 512 EV Project vehicles respectively as of the first quarter of 2013, with average hourly system load. The normalized median charging loads for Washington and Oregon are based on EV Project data from the first quarter of 2013. The normalized average hourly system load were calculated from hourly load data for the service territory of the Bonneville Power Authority, which includes 300,000 square miles in the Pacific Northwest, for the first three months of 2013.

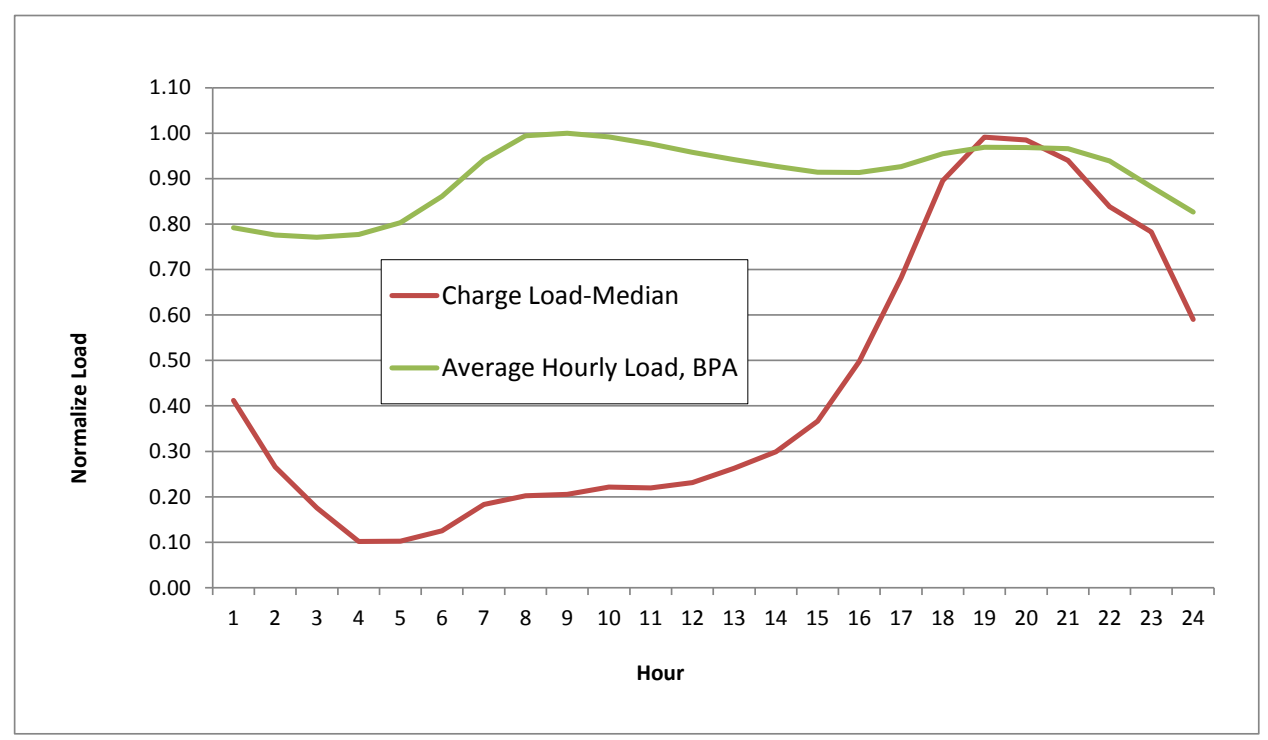

Figure 8. Washington State Charge Load vs. Average Hourly System Load Q1 2013 


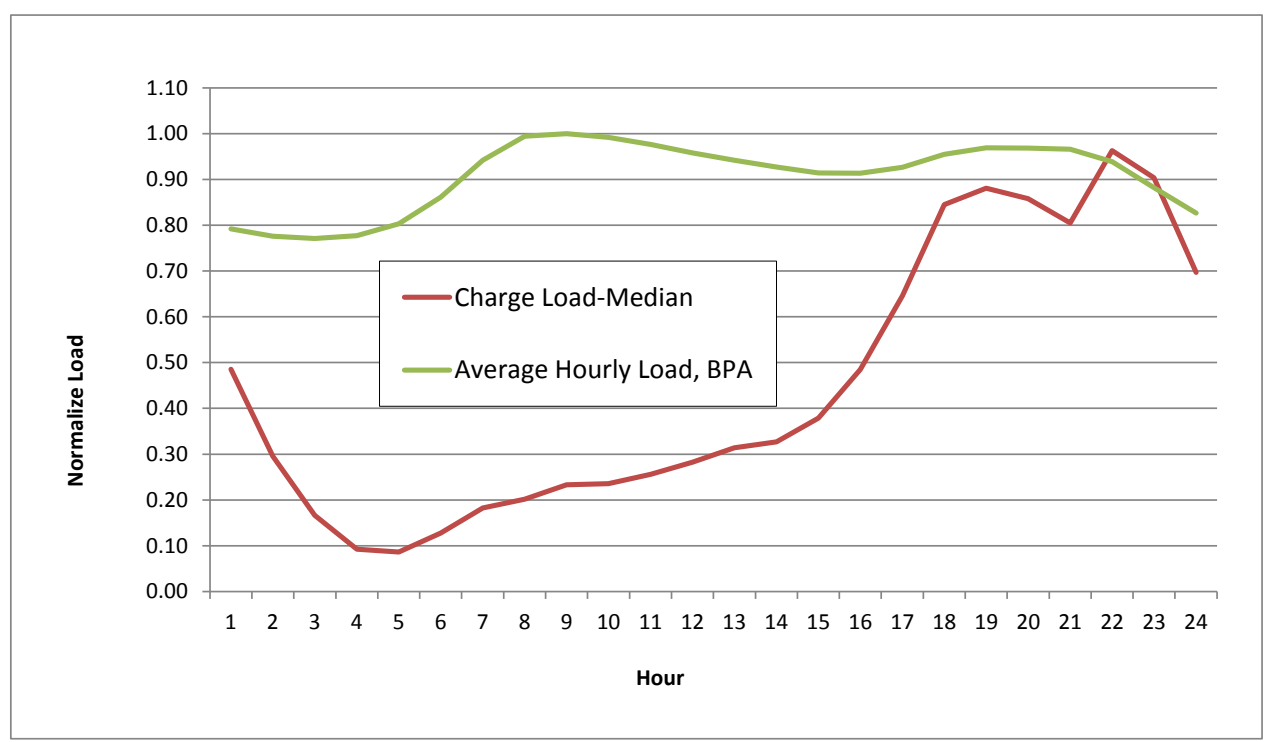

Figure 9. Oregon Charge Load vs. Average Hourly System Load Q1 2013

Figure 10 compares the normalized loads for PEV charging in San Diego, CA, with 725 EV Project vehicles as of the first quarter of 2013, with the average hourly system load data. The normalized median charging load for San Diego, CA is based on EV Project data from the first quarter of 2013. The normalized average hourly system load was calculated from hourly load data for the service territory of San Diego Gas and Electric for the first three months of 2013.

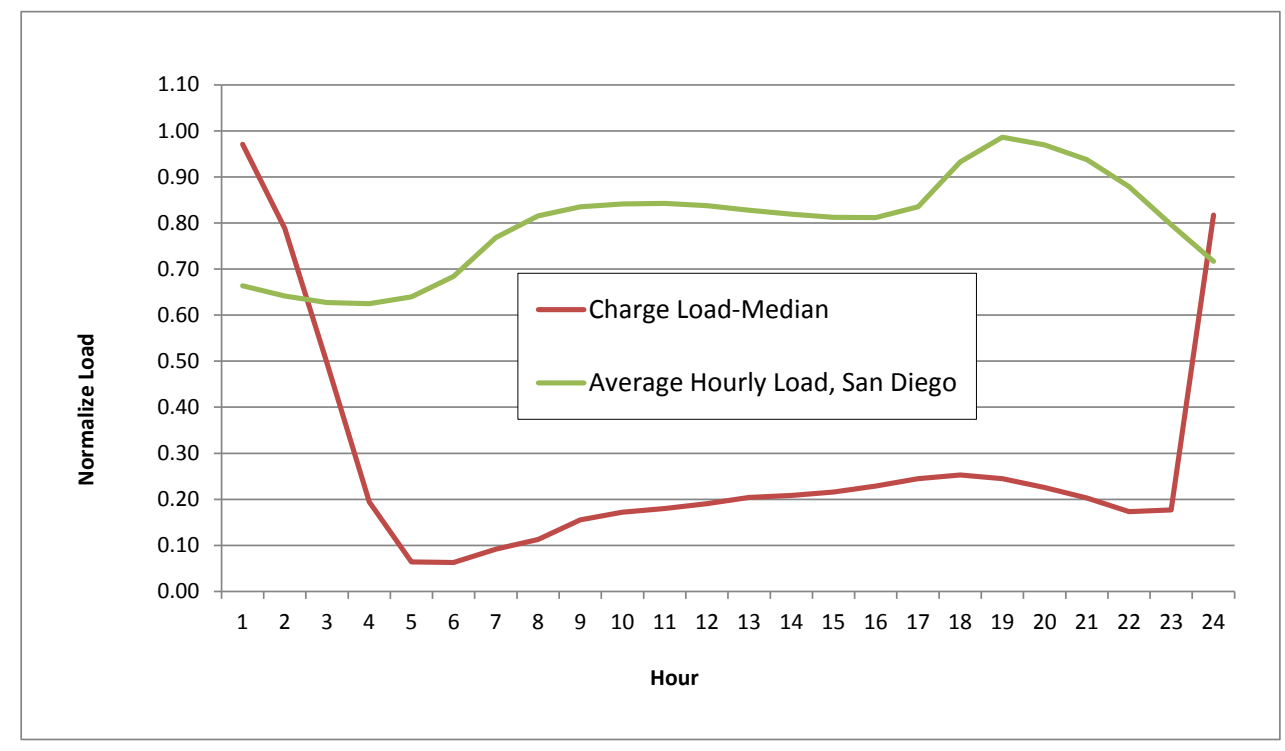

Figure 10. San Diego Charge Load vs. Average Hourly System Load Q1 2013

Figure 4 through Figure 8 above demonstrate that PEV owners in regions without TOU rates begin charging when returning home in the early evening. The timing of vehicle charging is closely correlated with the system peak demand for electricity in the first quarter of 2013 in all the five regions (Dallas-Frt. Worth, Houston, Washington DC, Philadelphia, and Washington State). Utility companies serving the regions represented in Figure 9 and Figure 10 (Oregon and 
San Diego, CA) offer TOU rates, which leads to many consumers choosing to delay PEV charging to the late evening and early morning hours.

Figure 11, Figure 12 and Figure 13 illustrate the coincidence between the annual peak load day in 2012 and PEV charging load for Dallas-Fort Worth, Houston, and Washington DC respectively. Figure 4 through Figure 10 above display average hourly system loads for the first quarter of 2013 for the regions represented, which illustrates that the timing of PEV charging coincides with system loads in those regions without TOU rate options. Here we consider the impact of PEV charging on the annual system peak, which is a key parameter for system planning.

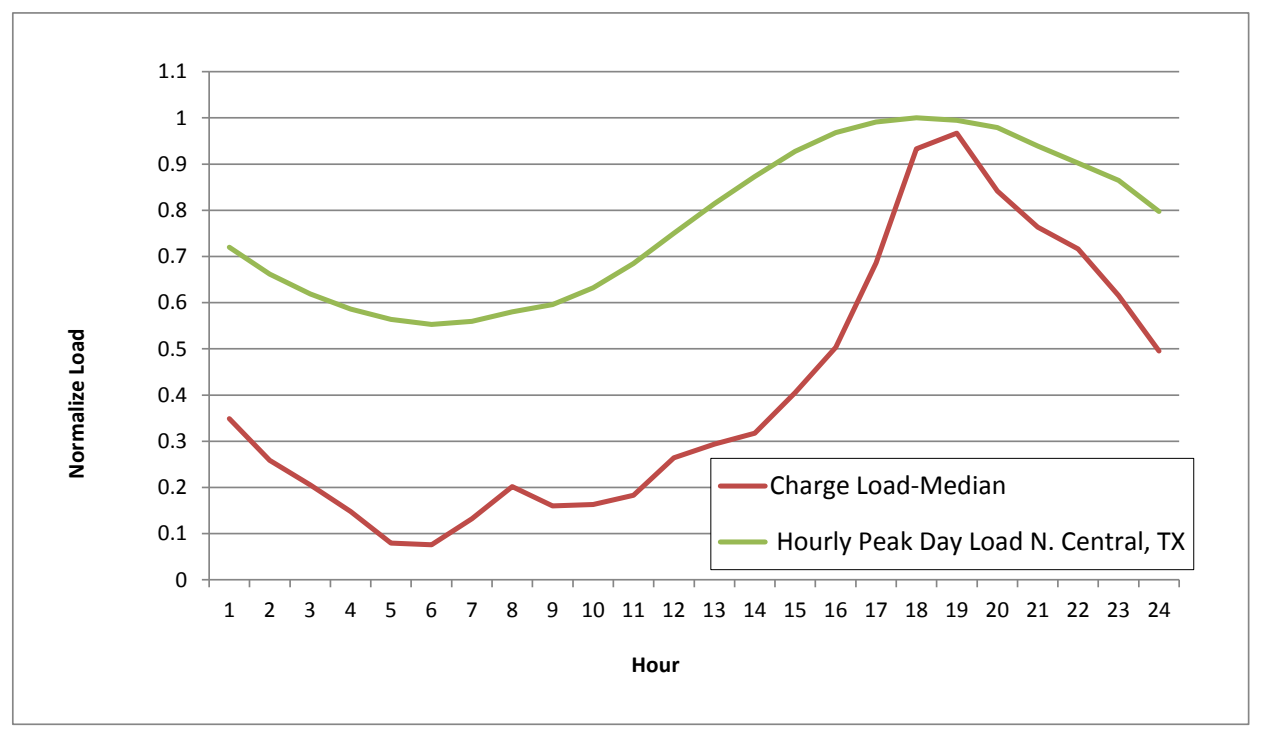

Figure 11. Dallas-Ft. Worth Charge Load Q3 2012 vs. Regional System Peak 2012

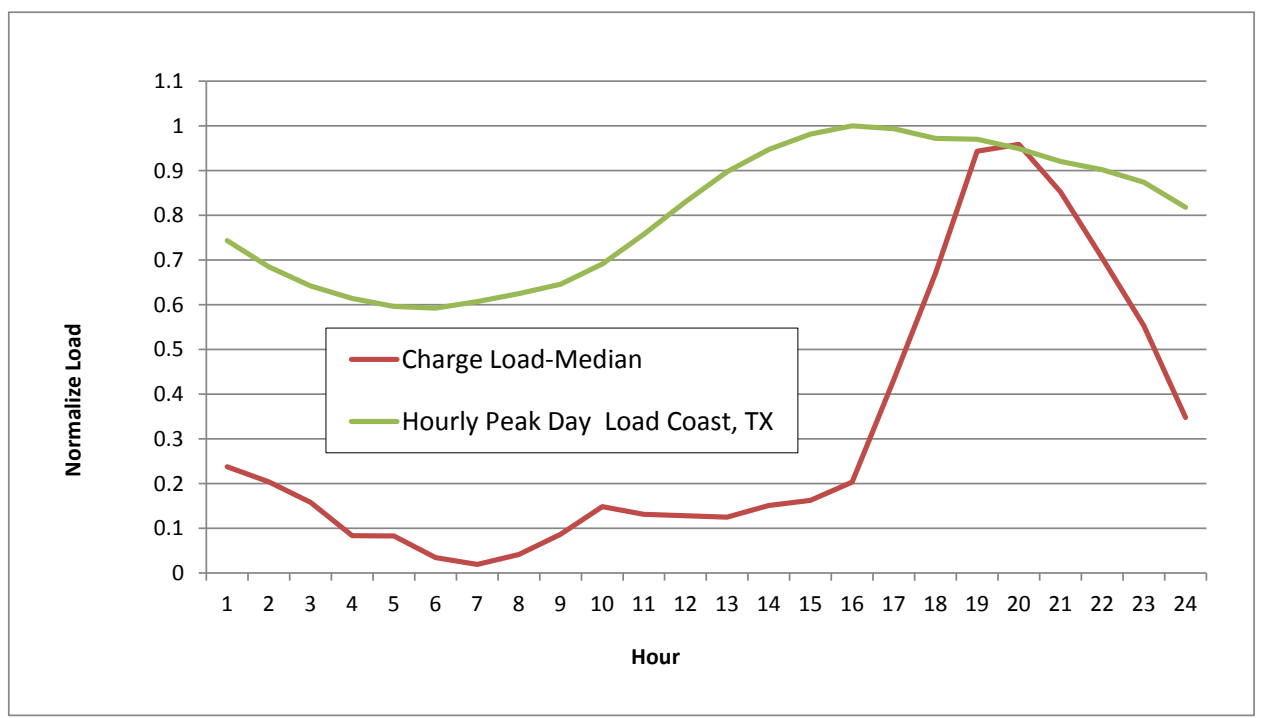

Figure 12. Houston Charge Load Q3 2012 vs. Regional System Peak 2012 


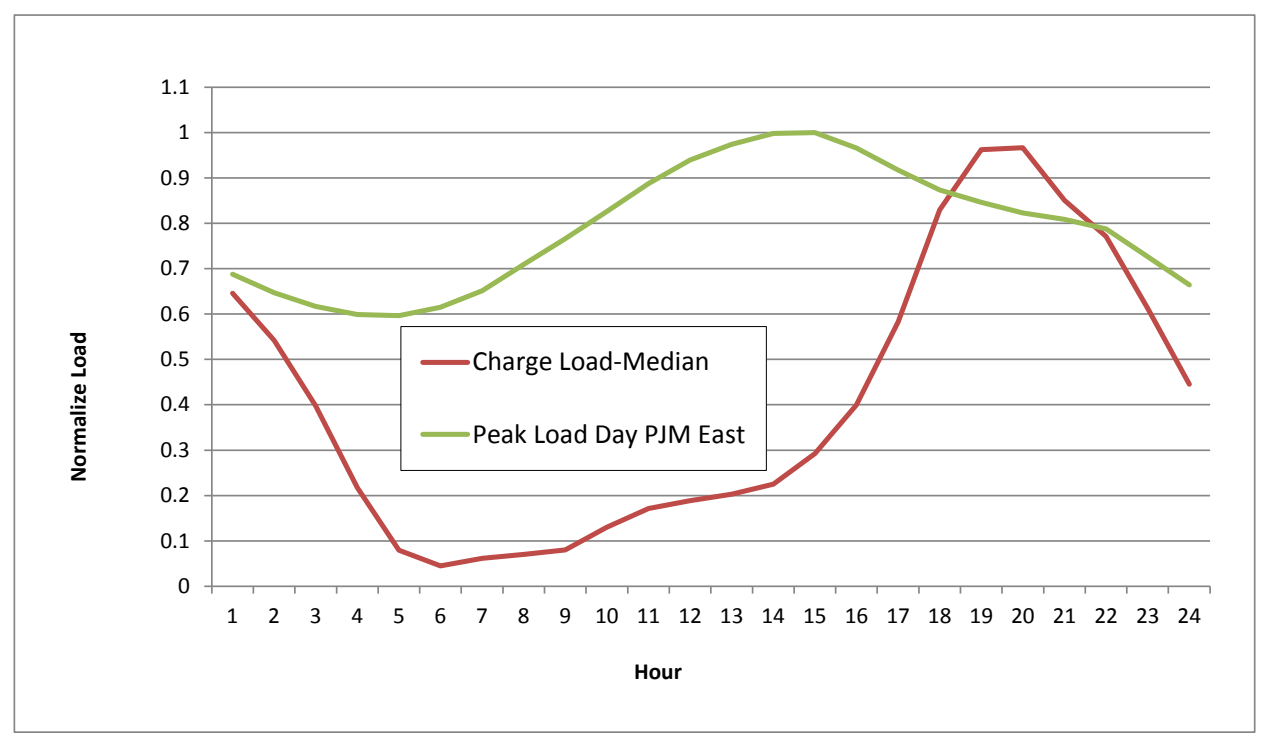

Figure 13. Washington, DC Charge Load Q3 2012 vs. Regional System Peak 2012

Figure 11 illustrates that the annual system peak in the Dallas-Ft. Worth region coincides with the peak demand for PEV charging in 2012. In the Houston region, peak demand for PEV charging occurs a few hours after the system load peaks, which occurred at 3:00 pm on June 26, 2012. Similarly, peak demand for PEV charging in Washington DC trails the annual peak system load in the eastern region of PJM's service territory. The eastern PJM region experienced its 2012 annual peak at 3:00 pm on July 18. Thus, the annual system peak demand in some regions may not coincide with peak demand for PEV charging, while Figure 4 through Figure 8 illustrate a coincidence between peak system load during the first quarter of 2013 and PEV charging.

While the aggregate charging load for EV Project participants is relatively low, as PEV adoption increases system peak loads could increase from PEV charging thus confirming what Hadley and Tsvetkova (2008) found in their regional PEV grid impact assessment.

Table 1 below contains the effective peak $(\mathrm{kW})$ demand per vehicle for all EV Project vehicles and in each of the seven regions analyzed above. The peak charging demand for the first quarter of 2013 is divided by the number of EV Project vehicles to arrive at a per vehicle effective peak demand value. In those regions where PEV owners begin charging in the early evening, these values can be used to estimate what the per-vehicle impact is on the system peak in areas where there PEV charging is coincident with system peak. 
Table 1. Effective Peak Demand per EV Project PEV Q1 2013

\begin{tabular}{lcccc}
\hline \multicolumn{1}{c}{ Region } & $\begin{array}{c}\text { Peak Charge } \\
\text { Load }\end{array}$ & Time of Day & $\begin{array}{c}\text { Number of EV } \\
\text { Project PEVs }\end{array}$ & $\begin{array}{c}\text { Effective Peak } \\
\text { Demand per PEV }\end{array}$ \\
\hline All & $5,315 \mathrm{~kW}$ & $12: 15 \mathrm{am}$ & 6,006 & $0.88 \mathrm{~kW}$ \\
Dallas-Ft. Worth & $237 \mathrm{~kW}$ & $7: 30 \mathrm{pm}$ & 189 & $1.25 \mathrm{~kW}$ \\
Houston & $107 \mathrm{~kW}$ & $7: 45 \mathrm{pm}$ & 75 & $1.42 \mathrm{~kW}$ \\
Washington, DC & $342 \mathrm{~kW}$ & $7: 45 \mathrm{pm}$ & 297 & $1.15 \mathrm{~kW}$ \\
Philadelphia, PA & $77 \mathrm{~kW}$ & $6: 30 \mathrm{pm}$ & 67 & $1.15 \mathrm{~kW}$ \\
Washington State & $816 \mathrm{~kW}$ & $7: 45 \mathrm{pm}$ & 807 & $0.99 \mathrm{~kW}$ \\
Oregon & $523 \mathrm{~kW}$ & $10: 15 \mathrm{pm}$ & 512 & $1.02 \mathrm{~kW}$ \\
San Diego & $1,333 \mathrm{~kW}$ & $1: 15 \mathrm{am}$ & 725 & $1.83 \mathrm{~kW}$ \\
\hline
\end{tabular}

Although the peak load impacts from EV Project vehicles in the regions analyzed here is minimal, as PEV adoption rates rise in the coming decade there is the potential to increase the peak demand for power in during certain times of the year without efforts to indirectly or directly shift vehicle charging to off-peak periods. Expanding peak capacity to meet the demand from PEV charging could be costly; forecasting specific costs to expand generation, transmission, and generation capacity in these regions is beyond the scope of this project.

Figure 14 indicates the potential impact on regional peak demand during the three month period, January through March, for power given 500,000 additional PEVs being introduced in each of the five regions where PEV charging is coincident with system peak during the first quarter of 2013. The values in Figure 14 were calculated by taking the peak regional system demand during the first quarter of 2013 and dividing it by 500,000 PEVs times the effective peak demand values in Table 1 above.

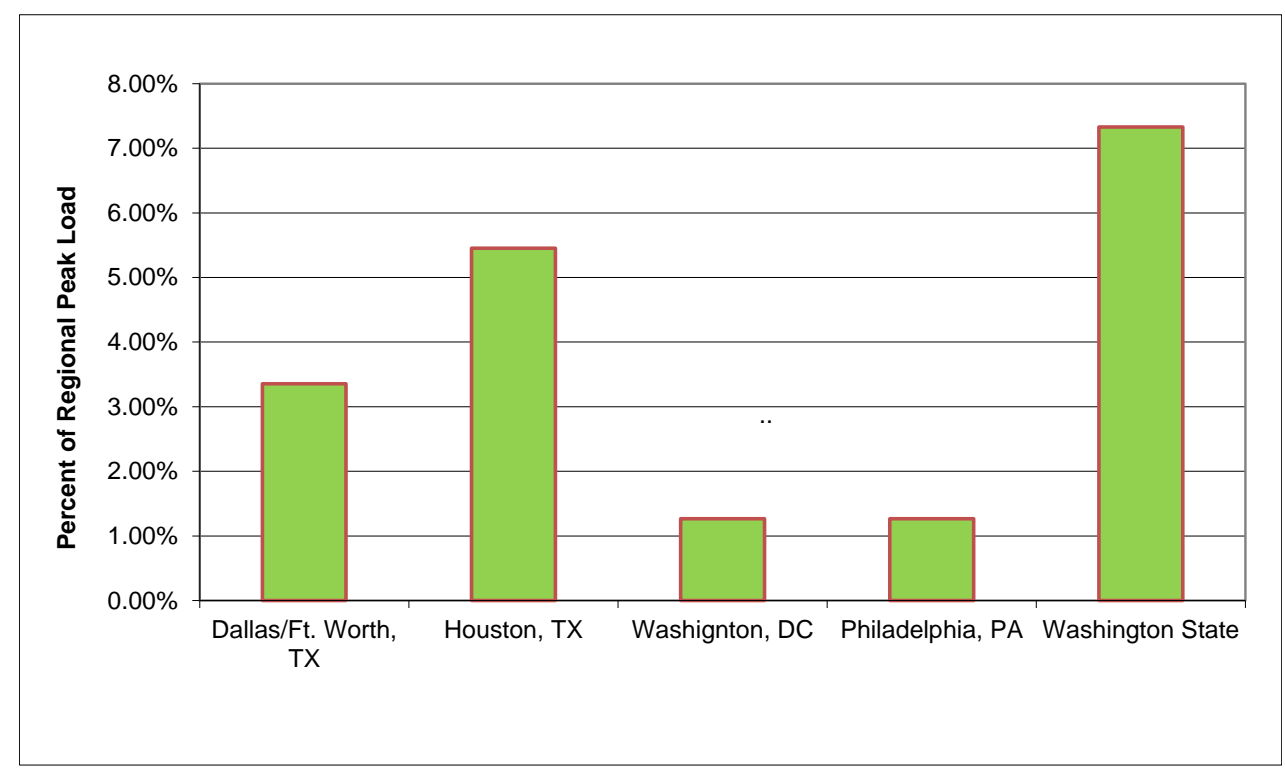

Figure 14. Percent Increase in Regional Peak Load with 500,000 PEVs 
Based on Figure 14 above, every 500,000 additional vehicles in the north central region of Texas would increase the peak demand during the first three months of the year for power by over three percent, while a similar increase in PEVs in the coastal region of Texas would increase peak demand by over five percent. An additional 500,000 PEVs located in Philadelphia or Washington DC would increase the peak demand for power during the time period of January through March in the eastern region of the PJM service territory by slightly over one percent and by over seven percent in Washington State. The analysis here is for illustrative purposes, as it is difficult to forecast PEV ownership reaching 500,000 vehicles in these regions. The Washington State region has 807 EV Project participating vehicles; a 100\% annual growth rate PEV ownership would take approximately 10 years to reach the 500,000 vehicle milestone. It should be noted, however, that 500,000 vehicles represent only 3.4 percent of all new car sales in 2012 .

In addition to the potential increased costs associated with increasing the peak demand for power due to PEV charging in regions without TOU rates, consumers end up spending more to charge their vehicles. Shifting PEV charging to off-peak hours when the price of electricity is historically lower would reduce the fuel costs associated with PEV ownership. Figure 15 below illustrates the potential to shift charging from the early evenings to the nighttime, using IVCI to eliminate all charging between the hours of 5:00 pm and 12:00 am and shifting the load to the hours from 12:00 am to 7:00 am.

Based on EV Project data the median delivered energy on a typical weekday in all regions and all charging locations is equal to $50.7 \mathrm{MWh}$. The scenario described above would shift 23.0 MWh of charging load, which occurs between 5:00 pm and 12:00 am, to the off-peak period between 12:00 am and 7:00 am. The 23 MWh is evenly distributed over the 7 hour off-peak period in Figure 15.

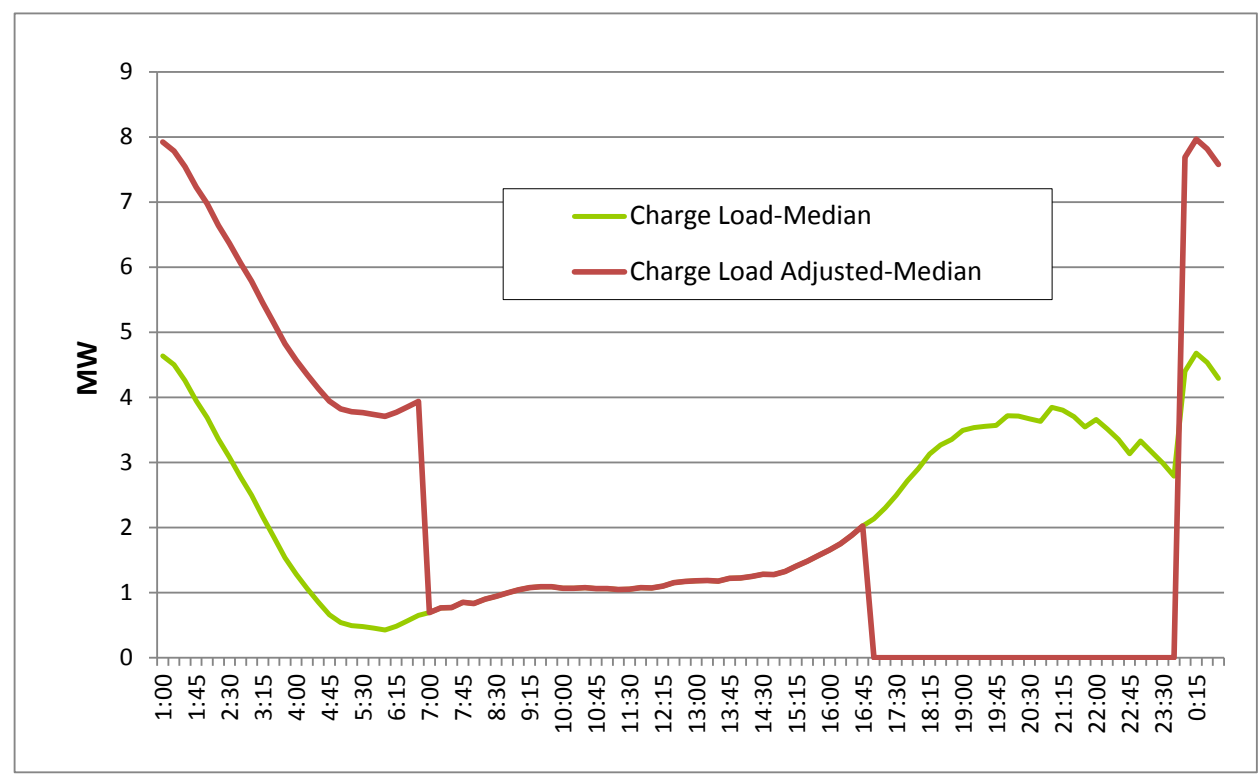

Figure 15. Charge Load vs. Charge Load Adjusted Q1 2013

Figure 16 presents the normalized median charge load and adjusted charge load and compares these to the normalized PJM system peak load for the first quarter of 2013. Obviously load profiles differ by region, but this comparison is helpful to visually see the potential for load 
shifting relative to the peak day load profile for the largest interconnect in the nation. Figure 16 illustrates the potential to move PEV charging load to off-peak periods, again using IVCI to accomplish this goal.

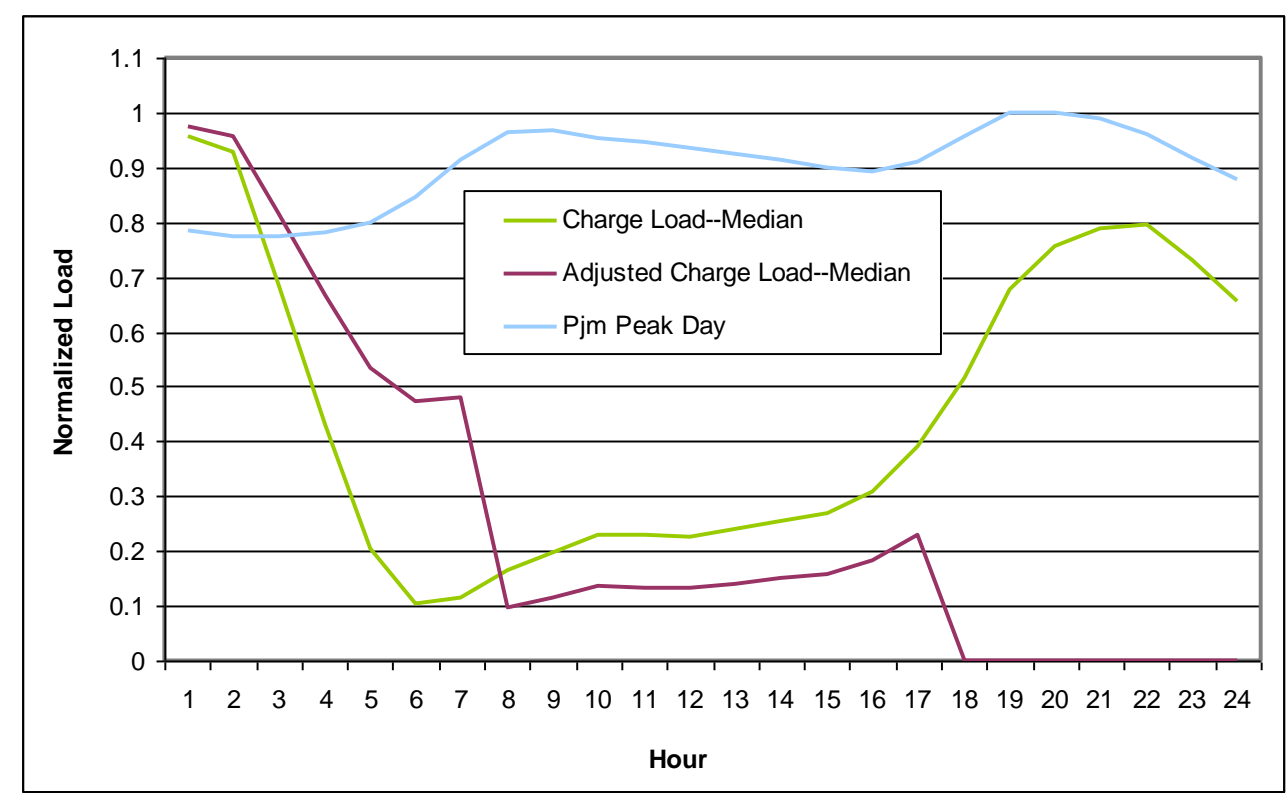

Figure 16. Normalized Charge Load, Charge Load Adjusted and PJM System Peak Day Q1 2013

Table 2 presents the total annual PEV charging cost savings based on shifting an average of $23 \mathrm{MWh}$ of load to off-peak daily as describe above. As discussed below, the differential between peak and off-peak rates vary by utility. Here we calculate annual reduced PEV charging expenses given three peak vs. off-peak rate differentials: $\$ 0.02 / \mathrm{kWh}, \$ 0.08 / \mathrm{kWh}$, and $\$ 0.15 / \mathrm{kWh}$. Total annual energy load shifting is simply calculated by multiplying $23 \mathrm{MWh}$ by 365 days in a year for a total of 8,395,000 kWh. Approximately one half of EV Project PEVs are currently being charged under TOU rates. Table 2 also presents the annual per vehicle savings assuming 3,000 of the approximately 6,000 EV Project vehicles owners would benefit from moving to a TOU rate. Finally, Table 2 provides estimates of net present value savings over ten years from shifting PEV charging load to off-peak periods.

Table 2. Annual PEV Charging Savings for PV Project Vehicles Moving to TOU Rates

\begin{tabular}{lccc}
\hline & \multicolumn{2}{c}{ Peak vs. Off-Peak Rate Differential } \\
& $\$ 0.02 / \mathrm{kWh}$ & $\$ 0.08 / \mathrm{kWh}$ & $\$ 0.15 / \mathrm{kWh}$ \\
\hline Annual PEV Charging Savings & $\$ 167,900$ & $\$ 671,600$ & $\$ 1,259,250$ \\
Annual Savings per PEV & $\$ 55.97$ & $\$ 223.87$ & $\$ 419.75$ \\
Net Present Value PEV Charging & $\$ 1,340,345$ & $\$ 5,361,381$ & $\$ 10,052,589$ \\
Savings* & $\$ 446.76$ & $\$ 1,787$ & $\$ 3,351$ \\
Net Present Value Savings per PEV* & \multicolumn{3}{c}{} \\
\hline *Assumes 10 years of savings, 2\% annual rate increases, and 6\% discount rate. & \\
\hline
\end{tabular}

The above analysis using PV Project data suggests that many PEV owners choose to charge their vehicles in the early evening hours, which could potentially correlate with the peak demand 
for power in certain regions during certain times of the year. The modeling by Hadley and Tsvetkova (2008) of regional PEV loads identified this as a potential concern associated with electrification of the nation's light vehicle fleet. Kintner-Meyer et al. (2007) assessed the potential of the nation's idle generating capacity to charge PEVs, finding that off-peak charging is a key mechanism to exploit this opportunity.

One of the key value propositions that the IVCI could deliver is shifting the timing of PEV charging to off-peak periods. This has real value to the system as it would reduce the need to invest in new generation, transmission and perhaps distribution infrastructure. In addition, shifting the current charging taking place during system peak load periods today by EV Project participants to off-peak periods could save hundreds of thousands of dollars in PEV fueling costs as indicated in Table 2 above. As the rate of PEV adoption increases pressure on regional peak demand for power and the potential PEV charging savings will grow accordingly.

\subsection{PEV Charging Load Timing in Areas with TOU Rate Options}

Approximately 43 percent of all EV Project vehicles are located in three California regions (Los Angles, San Diego, and San Francisco), which all offer TOU rate options for PEV charging. Figure 3 above illustrates a sharp peak in PEV charging load at 12:00 am, precisely when the offpeak rates in these regions takes effect. PEVs and EVSE offer consumers the option to set the timing of vehicle charging to take advantage of TOU rates. TOU rates represent an indirect approach to encouraging off-peak PEV charging, which seems to be effective given experience to date with EV Project participants. Figure 17 shows the normalized median load for EV charging for the three EV Project regions in California for the first quarter of 2013.

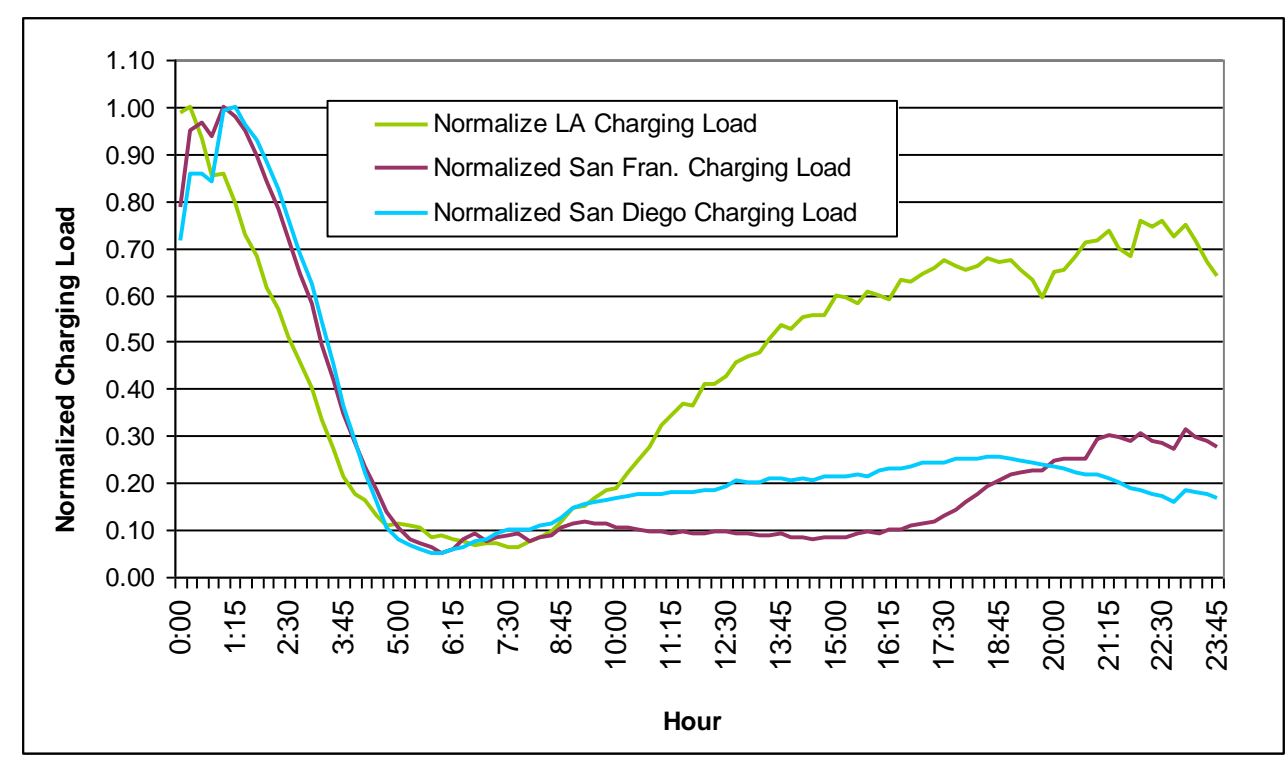

Figure 17. Normalized Median Charging Load CA Regions Q1 2013

Figure 17 clearly illustrates the spike in demand for PEV charging at 12:00 am in the three regions in California with EV Project participants, all of which have TOU rates available to customers. There are 577 EV Project vehicles as of the first quarter of 2013 in Los Angeles. The 
Los Angeles Department of Water and Power (LADWP) offers a discount of $2.5 \phi / \mathrm{kWh}$ for night and weekend charging under a special EV TOU rate. In the San Francisco and San Diego regions there are 1,310 and 725 EV Project vehicles as of the first quarter of 2013, respectively. In San Francisco PG\&E's E-9 experimental residential TOU service for low emissions vehicle customers has a differential between peak and off-peak as high as $27 \phi / \mathrm{kWh}$. San Diego Gas and Electric has a $13 \notin / \mathrm{kWh}$ peak and super off-peak differential for their EV TOU 2 rate. Both rates begin the off-peak or super off-peak period at 12:00 am.

It is interesting to note from Figure 17 that the consumer response to TOU rates in the Los Angeles EV Project area, which includes several smaller utilities in addition to the LADWP, is not as significant as consumer responses in San Francisco and San Diego. Thus the consumer response to off-peak rates in the Los Angeles area may be due to both the lower peak vs. off-peak rate offered by LADWP relative to the other regions and the fact that the smaller utilities may not offer TOU rates to PEV owners. To date, however, EV Project participants do seem to generally respond to indirect incentives to shift PEV charging to off-peak periods as clearly illustrated in Figure 17 above, but the size of the peak vs. off-peak rate differential may have an impact on the degree to which consumers respond to the incentive. A simple regression using these three rates and the percentage of PEV charging occurring during off-peak periods in therse three regions suggests that for every cent increase in the peak versus off-peak rate differential consumers shift 1.23 percentages of daily charging load to the off-peak period. This can be considered as an elasticity of load shifting. Additional analysis is needed with a larger dataset to further investigate the influence of peak versus off-peak rate differentials and the impacts on consumer charging behaviors.

As noted above, even charging off-peak in certain areas may lead to distribution constraints within certain neighborhoods. As noted by Taylor et al. (2010) PEV clusters and coincidental charging may exceed the capacity of secondary transformers. As PEV penetration rates increase in regions with TOU rates this could significantly increase power demand during these formerly low-cost, off-peak periods. This increased demand for power during off-peak periods could potentially increase nodal market prices (Wu et al., 2013). An IVCI could potentially address these challenges by staggering PEV charging in constrained neighborhoods to accommodate constraints within the distribution network and mitigate the wholesale market price impacts of PEV charging. Figure 18 illustrates the MW ramp in peak demand associated with PEV charging for the first quarter of 2013 for all charging locations on weekdays in San Francisco. There is a 1 MW+ ramp in demand associated with PEV charging from 11:00 pm to 12:00 am, when the offpeak rate takes effect. Figure 18 also illustrates an adjusted peak demand profile for PEV charging so as to smooth the ramp, but still deliver the same amount of energy before the morning commute. The 6.7 MWh of energy delivered between 12:00 am and 6:00 am is evenly distributed over the seven hour late evening and early morning time block. This is a simple representation to illustrate the potential to use an IVCI to smooth the demand associated with PEV charging during the late evening and early morning hours in response to potential distribution constraints. 


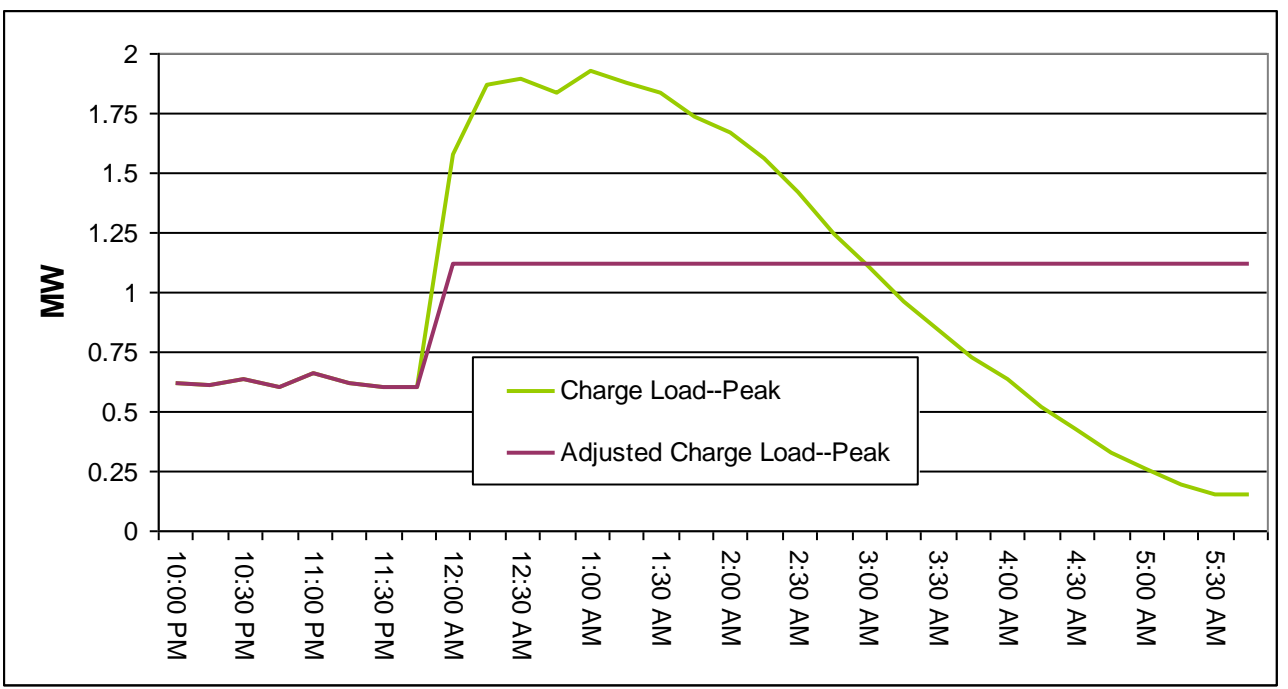

Figure 18. Peak Charge Load and Adjusted Charge Load San Francisco Q1 2013

The economic value of smoothing PEV charging loads to avoid local distribution constraints is very city specific and thus is beyond the scope of this project. However, the value that an IVCI can deliver, even in regions with TOU rate options, needs to be considered and better understood. 



\subsection{Providing Grid Support Services Using an IVCI and V2G Systems}

As noted above, a significant literature has emerged in the past decade assessing the potential that PEVs can offer serving as distributed energy storage devices. PEVs could provide a range of services, including peak-shaving, renewable energy balancing services, demand response, and reserve capacity. Some of these services can be provided by modulating the rate or timing of vehicle charging, while others would require a bi-directional grid connection using V2G systems. The lost economic potential is explored here given that the EVSE and smart grid infrastructure being deployed today lacks a coherent set of standards to facilitate an IVCI with V2G capabilities. No major PEV manufacturers currently offer vehicles with bi-directional power flow capabilities, although one major automobile manufacturer BMW has been experimenting with a prototype V2G-equipped electric vehicle. Furthermore, the impact from cycling batteries in vehicles to provide grid services is unknown creating a barrier to future commercialization. Thus, the economic potential evaluated here represents a future opportunity assuming these challenges are resolved. Unlocking the value PEVs can provide to the electric power system may be a key strategy to addressing the initial higher cost of PEVs relative to similar conventional gasoline fueled vehicles. The economics of $\mathrm{V} 2 \mathrm{G}$ are closely linked to the fact that vehicles are idle 90 percent of the time; the longer a vehicle that is idle and connected to a V2G capable IVCI, the greater the annual revenue potential for providing grid support services. EV Project data is first analyzed to determine how often PEV owners are connecting to the EVSE infrastructure. Next, the capacity of the existing EV Project fleet is calculated and the economic benefits from developing the capability to provide grid services are estimated assuming an IVCI, V2G capable vehicles, and successful business models.

The EV Project has generated significant amount of data on the EVSE infrastructure usage over the past two years. Table 3 below contains some of the key trends over the past five quarters, including data on the percentage of time that PEVs are connected to an EVSE unit and the percent of time when power is flowing to the vehicle.

Table 3. EV Project Statistics on EVSE Use Over Five Quarters

\begin{tabular}{|c|c|c|c|c|c|}
\hline All Regions & 2013_Q1 & 2012_Q4 & 2012_Q3 & 2012_Q2 & 2012_Q1 \\
\hline $\begin{array}{l}\text { Total number of EV } \\
\text { Project vehicles }\end{array}$ & 6,006 & 4,783 & 4,009 & 3,325 & 3,304 \\
\hline $\begin{array}{l}\text { Total number of charging } \\
\text { units }\end{array}$ & 8,580 & 6,939 & 5,877 & 4,821 & 4,289 \\
\hline Number of charging events & 501,193 & 388,606 & 289,364 & 250,953 & 227,314 \\
\hline $\begin{array}{l}\text { Total electricity consumed } \\
\text { (AC MWh) }\end{array}$ & $4,140.19$ & $3,212.30$ & $2,322.60$ & $2,094.49$ & $1,858.55$ \\
\hline $\begin{array}{l}\text { Percent of time with a } \\
\text { vehicle connected to } \\
\text { charging unit }\end{array}$ & $32 \%$ & $31 \%$ & $27 \%$ & $28 \%$ & $29 \%$ \\
\hline $\begin{array}{l}\text { Percent of time with a } \\
\text { vehicle drawing power } \\
\text { from charging unit }\end{array}$ & $7 \%$ & $6 \%$ & $6 \%$ & $6 \%$ & $6 \%$ \\
\hline
\end{tabular}


One of the important observations from the statistics in Table 3 above is the fact that on average an EVSE unit has a vehicle connected to it for about one third of the total hours in a given day. Figure 19 illustrates the percentage of charging units during weekdays that PEVs are connected to for all home level 2 EVSE units, of which all EV Project participants have, for the first quarter of 2013. Figure 20 illustrates the percentage of away from home level 2 chargers during weekdays that PEVs are connected to for the first quarter of 2013. Together the home and away level 2 chargers represent 8,508 of the total EV Project EVSE infrastructure of 8,580 chargers; the remaining 72 chargers are fast charging DC units.

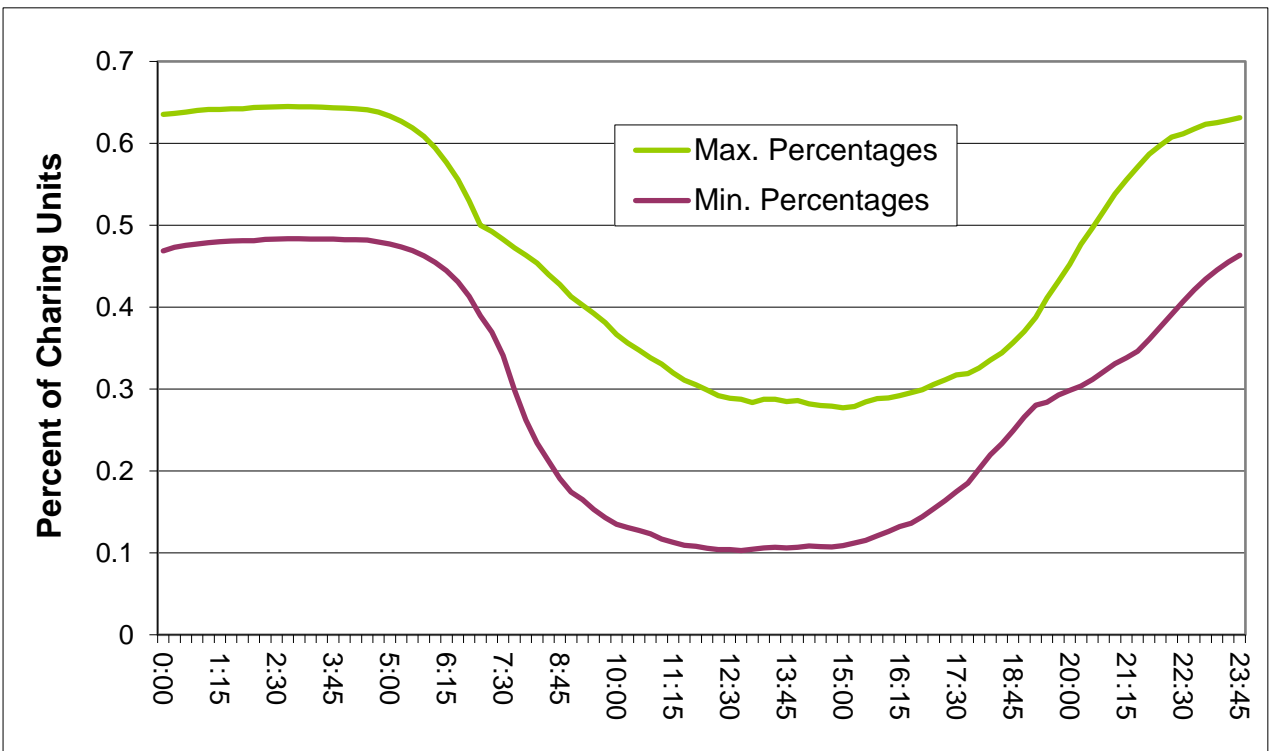

Figure 19. Percent of Residential Level 2 Chargers with Vehicle Connected by Time of Day

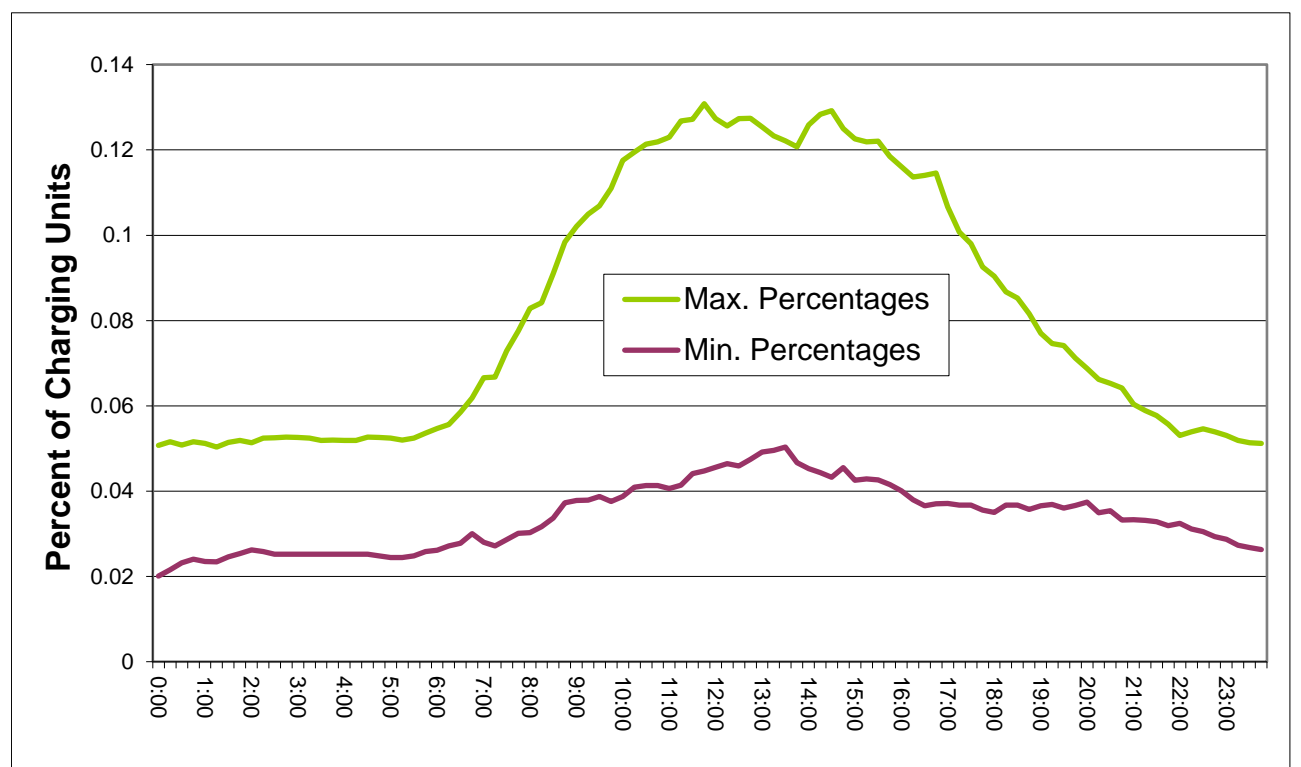

Figure 20. Percent of Away Level 2 Chargers with Vehicle Connected by Time of Day

Several observations can be made from Figure 19 and Figure 20 above, most notably that the EVSE infrastructure is being underutilized. Anywhere between 50 and 35 percent of home level 
2 chargers are not being used during the evening hours and between 95 and 87 percent of the away from home level 2 chargers are not being used during the daytime hours. One interpretation from these data is that PEVs may not always be parked at the homes with the vehicle chargers or the owners do not need to charge their vehicles everyday given the adequate battery storage capacity of their PEVs. If, however, PEV owners could generate revenue from providing grid services from just being connected to the grid, then this could potentially change behaviors.

EV Project data also suggests that PEVs are connected to chargers much longer than it takes to fully charge the vehicles. As noted in Table 3 above in the first quarter of 2013 PEVs were drawing power from chargers only 7 percent of the time, while on average 32 percent of the time a vehicle is connected to a charger. The first quarter 2013 EV Project Electric Vehicle Charging Infrastructure Summary Report indicates that the average number of hours per charging event with an electric vehicle connected to a home level 2 charger is 12 hours, while the average length of time with vehicles drawing power per charging event is just 2.5 hours. For nonresidential level 2 chargers the average length of connection during weekday charging events is 7.8 hours and 3.5 hours on average when power is flowing to the vehicle during weekday charging events. These observations suggest that there is significant potential to utilize the emerging PEV fleet connected to a V2G capable IVCI to provide grid support services.

The value of grid services is proportional to the $\mathrm{kW}$ power rating of the $\mathrm{V} 2 \mathrm{G}$ grid interface. This can be limited by on-board PEV electronics and/or the wire connection of the EVSE. The J1772 standard for level 2 charging has maximum power capacity of $19.2 \mathrm{~kW}$ ( 240 volts at 80 amps); although the majority of residential charging units being deployed today are limited to much lower power ratings $(3.3 \mathrm{~kW}-6.6 \mathrm{~kW})$. Here we assess the value of grid support services of the EV Project PEV fleet based on three power rating assumptions: 5kW, 10kW, \& 15kW; obviously the value of grid services rises linearly with the power rating of the V2G grid interface. With approximately 6,000 EV Projects vehicles participating in the program, these vehicles represent a capacity resource based on the $5 \mathrm{~kW}, 10 \mathrm{~kW}, \& 15 \mathrm{~kW}$ grid power connection assumptions of 30MW, 60MW, and 90MW respectively. Even a relatively small number of PEVs can represent a significant power resource for the grid.

As noted above, the number of hours that a PEV is connected to a V2G capable IVCI determines how many hours they can participate in markets for grid support services. Regional grid operators are constantly procuring - 8,760 hours annually — various reliability services. Furthermore, the SOC of the vehicle also determines what type of grid service the PEV can reliably supply. It is important to note that providing frequency response regulation services would require that the batteries not be fully charged to allow V2G systems to deliver regulation down services. However, for simplicity here it is assumed that the hours that the EV Project vehicle fleet is eligible to participate in reserve capacity markets, it is assumed that the vehicle is plugged in to an EVSE unit and is not charging or it is connected but not charging as it may be waiting for midnight to start charging. The total hours charging for the first quarter of 2013 (7\% $\mathrm{x} 8,760 \mathrm{hrs}$. in year $=613 \mathrm{hrs}$.) is subtracted from total hours that vehicles are connected to a charging unit $(32 \%$ x $8,760 \mathrm{hrs} .=2,803 \mathrm{hrs}$.) to calculate the total hours available each year for providing grid services of 2,190. Gross revenues for providing grid support services are also calculated assuming that consumers are incentivized to connect more frequently to chargers. The 32 percent from Table 3 above is approximately doubled to 65 percent to arrive at total hours 
available to provide grid support services of 5,081, which is used to calculate gross revenue projections below in addition to the base case.

As noted above, there are a range of services that PEVs with a fully functional IVCI with V2G capabilities could provide. Letendre and Kempton (2002) demonstrate that the two ancillary services to support grid reliability known as spinning reserves and frequency regulation are the most valuable. Furthermore, these services are traded in several regional wholesale power markets, thus their economic value is readily transparent. Table 4 presents average annual market clearing prices for spinning reserves and regulation in 2011 for several RTO/ISO regions taken from MacDonald et al. (2012).

Table 4. Annual Average Market Clearing Prices 2011 for Regulation and Spinning Reserves

\begin{tabular}{|c|c|c|}
\hline ISO (Reserve Zone) & Regulation & 10-min Spinning Reserves \\
\hline CAISO (South)^ & $\$ 9.60 / \mathrm{MW}-\mathrm{h}$ & $\$ 9.45 / \mathrm{MW}-\mathrm{h}$ \\
\hline CAISO (North)^ & $\$ 8.07 / \mathrm{MW}-\mathrm{h}$ & $\$ 7.23 / \mathrm{MW}-\mathrm{h}$ \\
\hline ERCOT $^{\wedge}$ & $\$ 15.63 / \mathrm{MW}-\mathrm{h}$ & \$22.92/MW-h \\
\hline MISO & $\$ 10.83 / \mathrm{MW}-\mathrm{h}$ & $\$ 4.03 / \mathrm{MW}-\mathrm{h}$ \\
\hline PJM $^{*}$ & \$16.42/MW-h & \$7.91/MW-h \\
\hline NYISO (East) & \$11.80/MW-h & \$7.41/MW-h \\
\hline NYISO (West) & $\$ 11.80 / \mathrm{MW}-\mathrm{h}$ & \$3.37/MW-h \\
\hline ISO-NE $^{*}$ & $\$ 7.16 / \mathrm{MW}-\mathrm{h}$ & $\mathrm{n} / \mathrm{a}$ \\
\hline \multicolumn{3}{|c|}{$\begin{array}{l}\text { Source: Table 1, MacDonald et al., } 2012 \\
{ }^{\wedge} \text { These regions have separate regulation up and down markets; a simple average of the two annual prices was } \\
\text { taken. } \\
\text { *Real time market data, all other data is from day-ahead markets. }\end{array}$} \\
\hline
\end{tabular}

The lowest and highest market clearing prices for regulation and spinning reserves from Table 4 were used to calculate potential gross revenues for the fleet of EV Project vehicles, assuming the three plug connection ratings above. For spinning reserves, the ERCOT 2011 seems to be an anomaly so the second highest annual average market price was used for the gross revenue calculations. Gross revenues were also calculated assuming two different scenarios regarding the number of hours in a year when the PEV would be connected and providing grid support services. Table 5 and Table 6 present annual gross revenue estimates for each of these scenario for regulation and spinning reserves respectively. The concept of V2GHalf has been developed indicating no reverse flow of power to the grid, simply modulating the rate of charge to provide frequency response regulation. Here the value of full function V2G is analyzed, thus the potential gross revenues under a V2GHalf scenario would be slightly less than half of these presented in Table 5 as the one half of the gross revenues are discounted over ten years to present value dollars.

Table 5. Revenue Potential for EV Project Vehicle Fleet Providing Regulation Services (2011 Market Prices) Applying Full V2G Capabilities

\begin{tabular}{lcccc}
\hline & Power Ratings & $30 \mathrm{MW}$ & $60 \mathrm{MW}$ & $90 \mathrm{MW}$ \\
\hline Min. Mkt. Value & Current Hours & $\$ 470,412$ & $\$ 940,824$ & $\$ 1,411,236$
\end{tabular}




\begin{tabular}{ccccc}
\hline$(\$ 7.16 / \mathrm{MW}-\mathrm{h})$ & $\begin{array}{c}(2,190) \\
\text { Expanded Hours } \\
(5,081)\end{array}$ & $\$ 1,091,398$ & $\$ 2,182,797$ & $\$ 3,274,196$ \\
$\begin{array}{c}\text { Current Hours } \\
(2,190)\end{array}$ & $\$ 1,078,794$ & $\$ 2,157,588$ & $\$ 3,236,382$ \\
$\begin{array}{c}\text { Max Mkt. Value } \\
(\$ 16.42 / \text { MW-h })\end{array}$ & $\begin{array}{c}\text { Expanded Hours } \\
(5,081)\end{array}$ & $\$ 2,502,900$ & $\$ 5,005,801$ & $\$ 7,508,701$ \\
\hline
\end{tabular}

Table 6. Revenue Potential for EV Project Vehicle Fleet Providing Spinning Reserve Services (2011 Market Prices) Applying Full V2G Capabilities

\begin{tabular}{|c|c|c|c|c|}
\hline & Power Ratings & $30 \mathrm{MW}$ & $60 \mathrm{MW}$ & $90 \mathrm{MW}$ \\
\hline \multirow{2}{*}{$\begin{array}{l}\text { Min. Mkt. Value } \\
\text { (\$3.37/MW-h) }\end{array}$} & $\begin{array}{c}\text { Current Hours } \\
(2,190)\end{array}$ & $\$ 221,409$ & $\$ 442,818$ & $\$ 664,227$ \\
\hline & $\begin{array}{c}\text { Expanded Hours } \\
(5,081)\end{array}$ & $\$ 513,689$ & $\$ 1,027,378$ & $\$ 1,541,067$ \\
\hline \multirow{2}{*}{$\begin{array}{l}\text { Max Mkt. Value } \\
(\$ 9.45 / \mathrm{MW}-\mathrm{h})\end{array}$} & $\begin{array}{c}\text { Current Hours } \\
\quad(2,190)\end{array}$ & $\$ 620,865$ & $\$ 1,241,730$ & $\$ 1,862,595$ \\
\hline & $\begin{array}{c}\text { Expanded Hours } \\
(5,081)\end{array}$ & $\$ 1,440,463$ & $\$ 2,880,927$ & $\$ 4,321,390$ \\
\hline
\end{tabular}

Based on Table 5 and Table 6 above, the gross revenue potential for the existing EV Project participant vehicles is significant. These gross revenue estimates are sensitive to the service being provided, the power rating of the grid connection, and the number of hours that vehicles are connected and able to provide these services. No attempt is made here to estimate the increased cost to vehicle owners due to battery degradation associated with increased cycling of vehicle battery systems to provide V2G services. Additional research is needed to characterize the costs associated with increased battery cycling and development of the V2G infrastructure.

Improvements in battery technology and strategies to mitigate the wear on battery systems from cycling to provide $\mathrm{V} 2 \mathrm{G}$ services will likely be required for $\mathrm{V} 2 \mathrm{G}$ to become economic for vehicle owners.

Figure 21considers the present value of gross revenues for individual vehicles using data from Table 5 and Table 6 above. These per vehicle present value gross revenue projections are based on the minimum and maximum market values for regulation and spinning reserves with a $10 \mathrm{~kW}$ grid connection providing services for 5,081 hours each year. The present value calculations span 10 years and again assume a 2 percent annual increase in market prices and a 6 percent discount rate. 


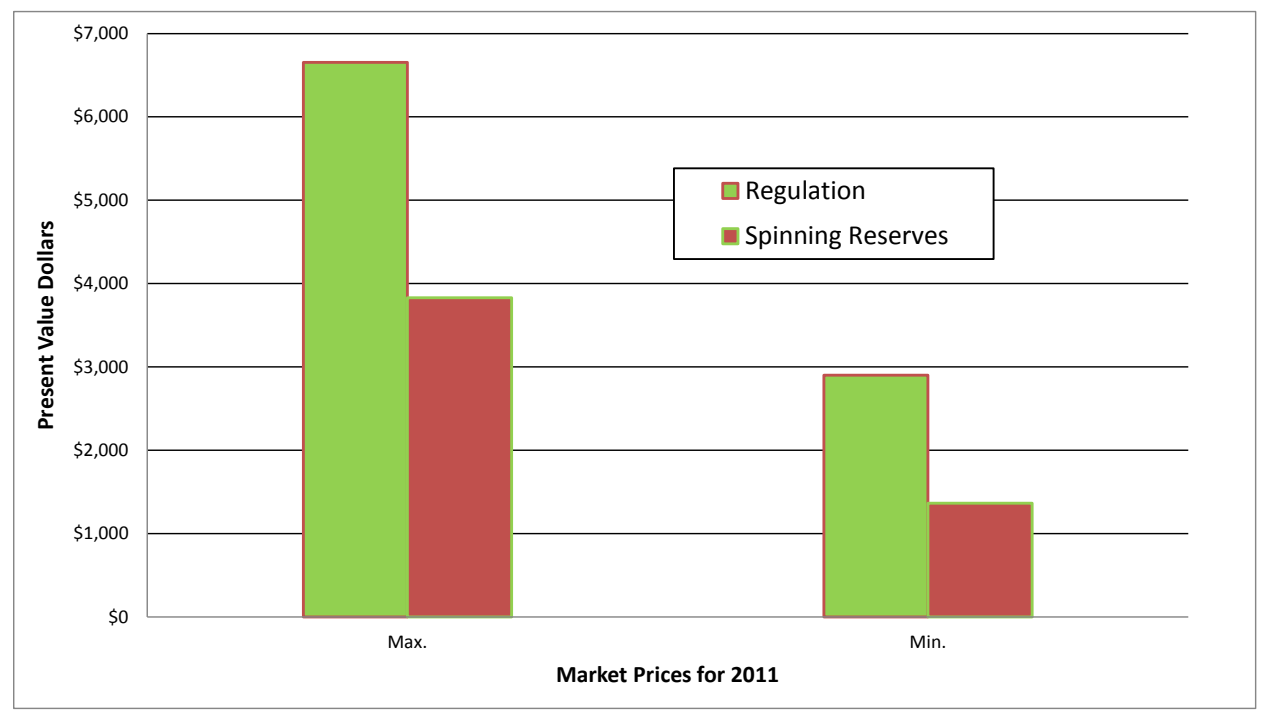

Figure 21. Present Value Gross Revenue per Vehicle Providing Grid Services 2011 Min. and Max. Market Values

The present value gross revenues over a 10-year period per vehicle are potentially significant, ranging from one thousand dollars to six thousand dollars. No attempt is made here to estimate the cost to vehicle owners from decreased battery life resulting from the increased cycling necessary to provide V2G services. However, future net V2G revenues and the lower fuel costs may help reach cost of ownership parity between PEVs and conventional gasoline vehicles.

Many barriers remain to unlocking these values including first and foremost the lack of an IVCI with V2G capabilities. Without underlying information exchange and control functionality, the emerging PEV, EVSE, and smart grid infrastructure is not capable of unlocking the value that PEVs offer as distributed grid resources. In addition, wholesale power market rules were not developed with small distributed resources in mind for providing these services and thus will need to be revised accordingly to allow PEVs to provide reliability services. There is an increasing interest among various stakeholders to allow PEVs and other demand-side resources to provide reliability services; thus the potential for market and regulatory reform exists. 


\subsection{Conclusions}

Electrification of the light-duty vehicle fleet offers the near-term potential to diversify fuels used for transportation. Dozens of studies on PEVs have been performed in the past decade assessing the petroleum displacement potential, emissions benefits, grid impacts, and the value that PEVs can deliver serving as distributed energy resources. These studies are by and large based on future scenarios when PEVs begin to represent a sizable portion of new vehicle sales.

Today, we are gaining real world experience with PEV owner behaviors and the grid impacts from vehicle charging based on thousands of PEVs that have been sold since 2010. The U.S. Department of Energy sponsored EV Project represents the largest PEV and EVSE deployment in the nation's history. Data on over 6,000 PEVs and over 8,500 EVSE are being gathered to better understand charging behaviors and the grid impacts of vehicle charging.

The substantial literature on PEV grid impacts and the value of V2G services recognizes the importance of communication and control between PEVs, EVSEs, and the emerging smart grid infrastructure. An IVCI allows grid operators to manage the timing of PEV charging and opens new opportunities for PEVs to compete in wholesale markets providing grid support services. However, the lack of a coordinated interoperability standards across the PEV charging infrastructure creates a formidable barrier to the development of IVCI. This report attempts to highlight the economic benefits of an IVCI using EV Project data.

Charging behaviors by EV Project participants demonstrates that consumers in regions without TOU rates choose to begin charging upon returning home from the daily commute. In some regions and during certain times of the year the potential exists whereby PEV charging could contribute to the peak demand for power. Increasing the peak demand for power on regional grids could eventually lead to increased investments in generation, transmission, and distribution assets. Based on the effective peak demand per vehicle calculated using EV Project data for the first quarter of 2013, 500,000 new PEVs would increase the peak demand for power in the PJM service territory by over one percent. In Texas, 500,000 new PEVs would increase the peak demand for power by five percent in the Houston area, by over three percent in the DallasFort Worth metropolitan area, and slightly over seven percent in Washington State based on load data for the first quarter of 2013 in each region.

Given that electricity cost are highest during peak hours, shifting PEV charging by EV Project participants that is currently occurring during system peak to off-peak could save PEV owners hundreds or perhaps thousands of dollars in reduced charging costs, depending on the rate differential between peak and off-peak periods, over the life of the vehicle. For all EV Project vehicles $(6,000 \mathrm{PEVs})$, over ten years the total potential savings from shifting charging to offpeak periods is well over one million dollars and perhaps as a high as $\$ 10$ million, assuming rate differential between peak and off-peak periods of $\$ 0.02 / \mathrm{kWh}$ and $\$ 0.15 / \mathrm{kWh}$ respectively.

EV Project participants located in regions with TOU rates are clearly responding to the offpeak rate incentive. When the off-peak rate takes effect, a sudden peak in demand for vehicle charging is clearly visible in the data. As noted earlier in this report, off-peak charging takes advantage of idle capacity and thus is preferred by utility companies. However, this spike in 
demand for vehicle charging has the potential to create constraints within the distribution network and put upward pressure on wholesale market prices during the evening hours. Neighborhoods with PEV clusters and coincidental charging may lead to demand beyond which secondary transformers can accommodate, requiring investments in upgrading distribution infrastructure. While calculating these potential costs from PEV charging is beyond the scope of this project, it is important to recognize these potential costs and the value that IVCI can provide staggering charging in PEV cluster neighborhoods to avoid distribution system investments. Additional research is needed to explore this issue by looking at federal level data in certain neighborhoods with higher than average PEV ownership and the development of screening tools to identify priorities in terms of IVCI investments.

Even in relatively small numbers, PEVs can represent a significant power resource for the grid. An IVCI with bi-direction V2G capabilities could allow PEVs to provide grid support services and thus generate a source of revenue for PEV owners when V2G vehicles become commercial, uncertainty on battery cycling impacts are better understood, and business models are developed. The fleet of EV Project vehicles represents a power resource between $30 \mathrm{MW}$ and $90 \mathrm{MW}$, depending on the power rating of the grid connection (5-15 kW). Aggregation of vehicle capacity could allow PEVs to participate in wholesale reserve capacity markets. One of the key insights from EV Project data is the fact that vehicles are connected to an EVSE much longer than is necessary to deliver a full charge. During these hours when the vehicles are not charging, they could potentially participate in wholesale power markets providing the high-value services of regulation and spinning reserves if the benefits outweigh the costs. This represents a future economic potential as current PEVs do not allow bi-directional power flows and the uncertainty of how V2G will impact battery life. No attempt is made here to estimate the cost associated with reduced battery life due to increased cycling to provide V2G services. Additional research is needed to better understand the net benefits to vehicle owners providing grid support services.

The annual gross revenue potential for providing these services using the fleet of EV Project vehicles is several hundred thousands of dollars to several million dollars annually depending on the power rating of the grid interface, the number of hours providing grid services, and the market being served. On a per vehicle basis, providing grid services can generate several thousands of dollars over the life of the vehicle. These values are based on the minimum and maximum average 2011 wholesale ancillary services prices, with a 10kW V2G grid connection, and providing services for 5,081 hours in the year, which translates to about 14 hours of V2G operations every day. This would require perhaps additional EVSE units in office parking lots to allow vehicle owners to provide grid services when parked at work. For V2GHalf, whereby no electricity is fed back into the grid, simply modulating the rate of charge, the benefit potential is limited up to half of that for the full V2G scenario, thus approximately $\$ 680$ - $\$ 3,325$ over a 10 year period. This scenario would not cause additional wear on vehicle battery systems. This economic potential could be realized with current PEV models, an emerging IVCI and through existing business models used by energy services and demand response providers.

The potential economic benefits of an IVCI are substantial. These will only rise significantly as PEV penetration rates accelerate in the coming decade. It is essential that relevant stakeholders acknowledge these costs and lost economic benefits and move quickly to develop the necessary communication and control standards to develop a nation-wide IVCI. 


\subsection{References}

Hadley, S. \& A. Tsvetkova, A. (2008). Potential impacts of plug-in hybrid electric vehicles on regional power generation, Oak Ridge National Laboratory: ORNL/TM-2007/150.

Idaho National Laboratory (INL). (2013) EV Project Electric Vehicle Charging Infrastructure Summary Report: April - June 2013

Kempton, W., \& Letendre, S. (1997). Electric vehicles as a new power source for electric utilities. Transportation Research-D, 2, 157-175.

Kempton, W. and Tomic, J. (2005). Vehicle-to-grid power implementation: From stabilizing the grid to supporting large-scale renewable energy. Journal of Power Sources. Volume 144, Issue 1, 1, 280-294.

Kintner-Meyer, M., Schneider, K., and Pratt, R. (2007). Impacts assessment of plug-in hybrid vehicles on electric utilities and regional U.S. power grids part 1: Technical analysis: Pacific Northwest National Laboratory, PNNL.

Letendre, S., Denholm, P., \& Lilienthal, P. (2006). Plug-in hybrid and all-electric vehicles: new load or new resource. Public Utilities Fortnightly, 144, 28 - 37.

Letendre, S., \& Kempton, W. (2002). V2G: a new model for power. Public Utilities Fortnightly, $140,16-26$.

MacDonald, J., Cappers, P., Callaway, D., Kiliccote, S. (2012). Demand response providing ancillary services A comparison of opportunities and challenges in the US wholesale markets. Presented at Grid-Interop 2012: Irving, TX.

Scott, M., Kintner-Meyer, M., Elliott, D., Warwick, W. (2007). Impact assessment of plug-in hybrids on electric utilities and regional U.S. power grids part 2: Economic assessment. Pacific Northwest National Laboratory., PNNL

Taylor, J., Maitra, A., Alexander, M., Brooks, D., Duvall, M. (2010). Evaluations of plug-in electric vehicle distribution system impacts. Power and Energy Society General Meeting, 2010 IEEE: 25-29 July.

Tuffner F. and Kintner-Meyer, M. (2011). Using electric vehicles to mitigate imbalance requirements associated with an increased penetration of wind generation. In Proceedings of the 2011 IEEE Power and Energy Society General Meeting, July 24-29.

Wu, Di, D.C. Aliprantis, and Ying Lei (2012) Load Scheduling and Dispatch for Aggregators of Plug-In Electric Vehicles. Smart Grid, IEEE Transactions. 3, 368 - 376. 



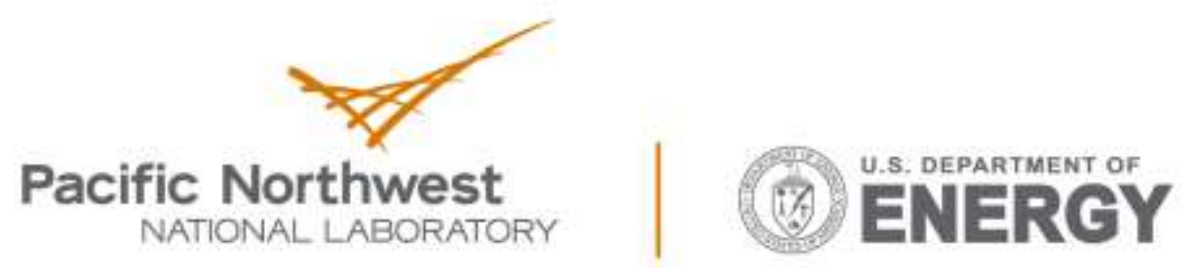

Proudly Operated by Batlelle Since 1965

902 Battelle Boulevard

P.O. Box 999

Richland, WA 99352

1-888-375-PNNL (7665)

www.pnnl.gov 